\title{
Complexity in a multinational enterprise's global supply chain and its international business performance: A bane or a boon?
}

\author{
Amalesh Sharma ${ }^{1}$, \\ V. Kumar $2,3,4,5$, \\ Sourav Bikash Borah ${ }^{5}$ and \\ Anirban Adhikary ${ }^{6}$
}

\footnotetext{
${ }^{1}$ Mays Business School, Texas A\&M University, College Station, TX 77843, USA; ${ }^{2}$ Tobin College of Business, St. John's University, New York, NY, USA;

${ }^{3}$ Indian School of Business, Hyderabad, India;

${ }^{4} \mathrm{MICA}$, Ahmedabad, India; ${ }^{5}$ Indian Institute of Management Ahmedabad, Ahmedabad, India;

${ }^{6}$ Indian Institute of Management Udaipur, Udaipur, India
}

\section{Correspondence:}

V Kumar, Tobin College of Business, St. John's University, New York, NY, USA e-mail: kumarv1@stjohns.edu

\begin{abstract}
The literature on marketing, operations management, and strategy has investigated the impacts of a firm's supplier network structure and complexity on its financial, environmental, and innovation performance. However, our understanding of how the global supply chain complexities of a multinational enterprise (MNE) affect its international business performance (IBP) is limited. We draw on both the business network theory and information search literature to propose that the various complexity dimensions (e.g., horizontal, vertical, and spatial) of an MNE's global supply chain have different influences on its subsequent IBP. We argue - and empirically validate - that collaboration, a network orchestration mechanism, enables an MNE to leverage the benefits of complex relationships. Using a dataset of 185 firms taken from multiple industries over 6 years, we show how such complexities have differential effects. In multiple post hoc analyses, we demonstrate how an MNE's marketing intensity, the interconnectedness among its supply members, and its top management team (TMT)'s international experience all have unique impacts. This study contributes to the existing literature on global supply chain complexity by demonstrating how it can influence MNEs' IBP. Moreover, we contribute to the strategic IBP literature by outlining effective global supply chain improvement strategies.
\end{abstract}

Journal of International Business Studies (2022) 53, 850-878.

https://doi.org/ 10.1057/s4 I 267-021-00497-0

Keywords: complexity; global supply chain; supply base collaboration; disintermediation; international business performance

\section{INTRODUCTION}

Managing international business performance (IBP) is a critical task for multinational enterprises (MNEs) ${ }^{1}$ due to the complex nature of international business (IB) operations (Hult, Ketchen, Griffith, Chabowski, Hamman, Dykes, Pollitte, \& Cavusgil, 2008). As new institutional forms such as the "global factory" (Grunwald \& Flamm, 1985) emerge, the role of global supply chains has become an integral part of MNE strategies. As firms start externalizing activities across the value chain, MNE managers have to rely on new ways to gain access to knowledge in international markets (Buckley \& Tian, 2017), such as leveraging the global supply chain. While IB research has investigated strategies such as the
Received: 10 October 2020

Revised: 14 September 2021

Accepted: 13 October 2021

Online publication date: 7 March 2022 
internationalization of R\&D activities and developing local subsidiaries, the role of supply networks - a major source of external knowledge (Crescenzi \& Gagliardi, 2018) - has received less attention. Research has outlined the effect of supply network structure on IBP (Sharma, Kumar, Yan, Borah, \& Adhikary, 2019). However, to date, researchers have not acknowledged the effects on IBP of a variety of complex interactions between multiple sub-systems (Simon, 1972) in the supply chain, which may undermine firms' ability to access local markets. Nevertheless, operations management research has shown that the structure and complexity of a firm's supplier network play a vital role in information flow, influencing both financial and innovation performance (Lu \& Shang, 2017; Sharma, Pathak, Borah, \& Adhikary, 2020). For the differences between network structure and complexity, see WA-Table 1.

Apart from the theoretical implications of increasing complexity in supply chains, managerial practices highlight the need for new tools to manage this phenomenon. A recent McKinsey article suggests that the more complex the supply chain, the greater the risk of disruption - which can cause a loss of up to $45 \%$ of yearly EBITDA per decade $^{3}$. Moreover, good management of global supplier relationships can positively impact a firm's IBP in multiple ways. A recent Accenture study, for example, suggests that a global supplier base provides market intelligence that positively influences $\mathrm{IBP}^{4}$, an argument supported by sourcing scholars. Firms enmeshed in a global supply chain gain information and knowledge through these distant relationships, aiding the development of insightful business strategies (Pathak, Dilts, \& Biswas, 2007). However, when a global supply chain becomes complex, the flow of information and knowledge can be interrupted, leading to an increase in costs and risks, affecting a firm's ability to achieve insights, and consequently adversely influencing IBP.

The key goal of managing complexity is to eliminate redundancies in the global supply chain to ensure lean, streamlined operation. A wellmanaged supply chain can ensure continuous product availability and, consequently, long-term system-wide success and profitability, as firms have learned the hard way, whether during the current COVID-19 pandemic or from previous disruptive events such as the Fukushima nuclear disaster. Ensuring that a complex network of material and information continues to flow smoothly, however, requires a greater number of interfaces "to be managed, monitored, and coordinated" (Bode \& Wagner, 2015, p. 218). Fundamentally, firms must continuously monitor complexity in the global supply chain, and, if events outside their control threaten to damage the smooth flow of goods or information, take whatever measures are available to them to reduce the effects. To devise and initiate the necessary strategies to achieve this broad aim, managers must consider multiple complexity dimensions within the global supply network: horizontal complexity (HC) (the width of the supply base); vertical complexity (VC) (the depth of the supply base); and spatial complexity (SC) (the geographical dispersion of the supply base), all of which may affect IBP differently (Lu \& Shang, 2017; Sharma et al., 2020).

We argue that the effects on IBP of the three network complexity dimensions outlined above may be fundamentally different than those on performance in general. Theoretically, multiple contingency factors, such as economic development, business conditions, resource availability, and customer expectations, can challenge success in international markets (Zhou, Brown, Dev, \& Agarwal, 2007). The challenges associated with IBP are different; hence, the relationship between network complexity and IBP differs in nature and magnitude from the relationship between network complexity and performance. Specifically, these differences can be seen in regard to knowledge acquisition, knowledge transfer, recombination, and costs and risks.

First, from the perspective of knowledge acquisition, a supplier's role is especially important in global markets. Global suppliers are a major source of the external knowledge which a firm must acquire to succeed in international markets (Crescenzi \& Gagliardi, 2018). In contrast, firms rely substantially less on suppliers in domestic markets, where they principally acquire knowledge from home-country research and development (R\&D) activities (Belderbos, Leten, \& Suzuki, 2013) when creating products and services. Hence, as a firm's dependence on suppliers is greater when it needs to acquire information about global markets, we argue that supply network complexity will have a differential effect for domestic business performance and IBP, which the literature has not, to date, investigated.

Second, global supply relationship complexity creates unique challenges to knowledge transfer. Due to opportunistic behavior and inherent power 
dynamics, global supply chain members may be reluctant to share information with the focal firm, influencing IBP (Sharma et al., 2019). Increased network complexity can lead to greater challenges in terms of both collaboration and the non-sharing of information, increasing the risks and costs associated with information acquisition and management. However, these challenges may be less severe in domestic than international markets, as the focal firm may have access to multiple information sources in the home country, compensating for the lack of knowledge flow from suppliers (Berchicci, 2013).

Turning to the recombination of knowledge, the complexities of a widely dispersed global supply chain can lead to the fragmentation of knowledge. In order to improve its IBP, a firm must acquire and then recombine knowledge to create products and services to exploit international markets. However, knowledge recombination can be complex when knowledge elements are scattered across multiple international markets, and each geographically dispersed unit only provides one "(part) of the puzzle" (Bos, Faems, \& Noseleit, 2017, p. 2301).

Finally, global supply chain complexity impacts costs and risks. The costs of operations can rise, and more potential risks threaten every individual relationship and transaction. For example, the greater the depth of the supply base, the more expensive and time-consuming it becomes to seek out knowledge sources, as it may be that multiple tiers of suppliers must be investigated to locate the knowledge sought. Clearly, these increased costs incurred negatively affect IBP.

This paper applies the tenets of business network theory and draws on the global supply chain and information search literature (Fleming, 2001) to answer the following question: How are the various dimensions of complexity (i.e., horizontal, vertical, and spatial) of a firm's global supply network related to its $I B P$ ? Extant research on business networks suggests that supplier support - that is, effective collaboration - can enhance the value a firm extracts from its supply network. As collaboration (SCL) within the supply network should influence the effects of complexity on a firm's IBP, we test the contingency effect of collaboration (connections among firms within the supply base) on a firm's supply network. Moreover, we explore focal firm disintermediation (SS), which refers to the connections between suppliers and their buyers' customers (Lu \& Shang, 2017) and may drive the effects of complexity on IBP. Collaboration and disintermediation are less tangible dimensions of global supply network complexity as they may not be directly visible to the focal firm (Lu \& Shang, 2017).

We test our hypotheses by leveraging data from 185 firms to construct multi-tier global supplier networks (see Figure 1 for an example of a complex global supplier network). By accounting for endogeneity and unobserved heterogeneity, we find that horizontal and vertical complexity both increase IBP at a decreasing rate, whereas spatial complexity decreases IBP at a decreasing rate. We also find a significant moderating effect for supply base collaboration and focal firm disintermediation.

We make multiple contributions to the extant IB literature and practice while emphasizing the link between global supply network complexity and IBP. Our first contribution is to the IB literature. Although in-depth research has been carried out in the global supply chain by IB scholars, their work has shed little light on its 'complexity' aspects and how these can affect a firm's IBP. We focus on this unexplored gap, thereby introducing an additional factor that may affect a firm's IBP, namely complexity, to the literature. Our second contribution is to business network theory, which we extend by broadening the idea of complexity and highlighting how different dimensions of complexity may have a differential effect on IBP. Our third contribution is to build on previous studies of collaboration in supply networks by measuring collaboration and showing how it can act as a network orchestration process that helps develop

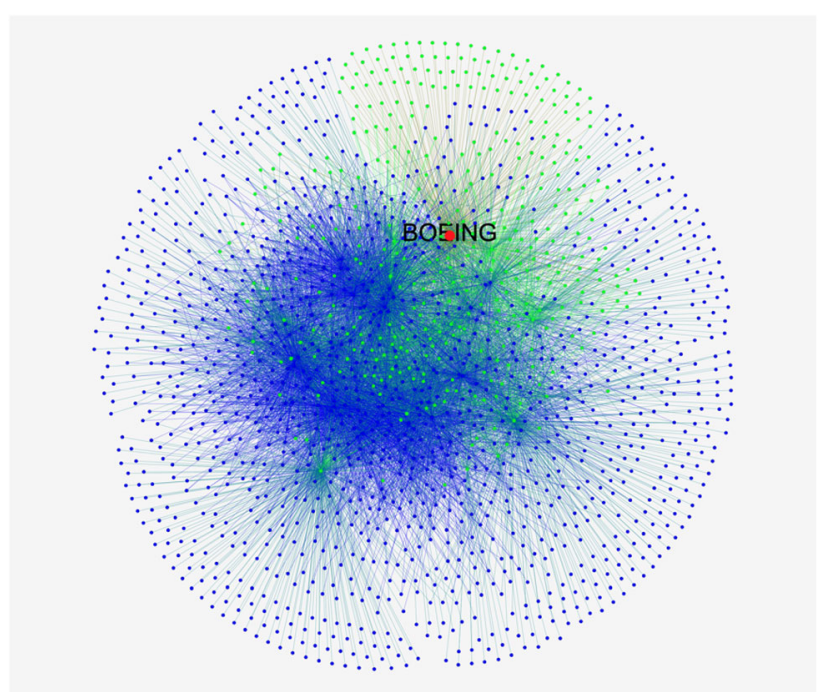

Figure 1 Multi-tier network of Boeing (Boeing marked as red. Tier 1 suppliers marked as green. Tier 2 suppliers marked as blue). 
capabilities and influences the effects of complexity. Consistent with business network theory, we show that collaboration is, indeed, a mechanism through which a firm can maximize its global supply chain returns. Our fourth and fifth contributions are to managerial practice. The first relates to the effects of focal firm disintermediation: by extending current knowledge and demonstrating how the impact of such disintermediation on IBP and complexity can be manipulated, we offer managers the possibility of enhancing performance. Finally, we use multiple post hoc analyses to outline and discuss further potential managerial strategies to enhance IBP. The next section provides a brief discussion of the related literature. WA-Table 2 presents the unique contributions of our study.

\section{RELATED LITERATURE}

\section{Networks, Complexity, and IBP}

Multiple studies investigating how organizational structures impact global supply chain structures and strategies and affect IBP (Germain, Claycomb, \& Dröge, 2008; Kano, 2018; Kim, 2007) argue that structural changes, such as decentralization and the localization of production, can affect supply chain strategies and performance. Network scholars have extended this stream of literature by emphasizing that firms gain added benefit from considering the entire supplier relationship as a network. Regarding suppliers in this way can not only further the development of local and distant relationships (Chen, 2003) but will unlock their potential to be organizational facilitators, allowing combinations of partners with differential capabilities to work together within the global value chain (Rullani, 1993). Hence, a global supplier network can facilitate internationalization by providing marketspecific and firm-specific knowledge, helping a firm "discover, create, actualize, and develop international market opportunities" (Chandra \& Wilkinson, 2017, pg. 692). A study of firms in the retail sector by Coe and Hess (2005), for example, emphasized the value of restructuring supply relationships in speeding up the internationalization process. Network research in IB has also focused on the role of networks in facilitating IBP. For example, the Uppsala tradition of IB (Johanson \& Vahlne, 2009), contingency theory (Bartlett \& Ghoshal, 2002), new internalization theory (Rugman \& Verbeke, 1992, 2008), and business network theory (Andersson, Forsgren, \& Holm, 2002) all acknowledge the importance of networks in an IB context.

A particular benefit of networks is that they provide firms with experiential learning, which is especially beneficial when firms are entering new foreign markets (Blomstermo, Eriksson, Lindstrand, \& Sharma, 2004). Recent network research carried out by Sharma et al. (2019) showed how firms could draw experiential learning from a multi-tier buyersupplier network, thus positively influencing their IBP. However, although the literature reveals a broad discussion of, on the one hand, the role of networks in general and how the network structure can facilitate IBP, in particular, and, on the other, the complexity which arises due to other organizational domains (Arregle, Miller, Hitt, \& Beamish, 2016; Ernst, 2005; Etemad, 2018; Nell \& Andersson, 2012), no study has examined how complexity in a global supply network may affect IBP.

\section{Complexity in Supply Chains}

Network research relies on two dominant views: structural and relational. The relational view focuses on the properties of individual ties, while the structural view emphasizes the presence or absence of linkages among network members (Shipilov \& Gawer, 2020). This paper adopts the structural view, which argues that connections or the lack thereof among network members facilitate or hinder the flow of knowledge and information, affecting performance (Burt, 1992; Coleman, 1988). Moreover, such connections or the lack thereof can also be a source of costs and risk. A structural view of supply networks can explain how the network complexity dimensions (i.e., horizontal, vertical, and spatial) affect different strategic outcomes, such as firm performance (Lu \& Shang, 2017). A structural perspective on inter-firm relationships has also started to gain traction in the marketing literature (Chakravarty, Zhou, \& Sharma, 2020; Fang, Lee, Palmatier, \& Han, 2016).

The structural view assumes that supply networks serve as a critical "conduit and source of information and knowledge access, and act as catalysts for the development and dissemination of new ideas, applications, and supply chain practices" (Bellamy, Ghosh, \& Hora, 2014, p. 359). However, social network theorists suggest that, while the information and knowledge obtained from supply networks can act as catalysts for a firm's innovation performance (Bellamy et al., 2014), financial performance (Basole, Ghosh, \& Hora, 2018), and IBP (Sharma et al., 2019), such networks can also cause complexity 
issues that increase the costs of managing suppliers, reduce collaboration among suppliers, and eliminate the joint value created (Choi, Dooley, \& Rungtusanatham, 2001; Pathak et al., 2007). As managers responsible for global operations govern their firms' global supply chains, overseeing processes such as selection of suppliers, selection of geographical sourcing, and so forth, they have an overview of the entire supply base and can influence its structure and complexity. Their knowledge depends on local managers (i.e., unit managers, area managers, region heads, etc.), who are aware of immediate operations and responsibilities (Gölgeci \& Kuivalainen, 2020); thus, a firm's global performance depends on the ability of a complex structure to function efficiently.

Moreover, while the effects of collaboration and disintermediation on various facets of firm operations have been discussed (e.g., Lu \& Shang, 2017), the role of collaboration and focal firm disintermediation in facilitating the effects of supply network complexity on IBP have received scant attention. Collaboration and disintermediation within the supply network are two critical components that may hinder or facilitate knowledge transfer, alter the cost burden, and change the risk structure ( $\mathrm{Lu}$ \& Shang, 2017), thus also affecting IBP; hence, it is important to investigate their contingency effects.

A summary of the literature discussed above on complexity and performance in general and complexity in supply chains and performance in particular - is summarized in WA-Table 3.

\section{THEORETICAL BACKGROUND, HYPOTHESIS DEVELOPMENT, AND CONCEPTUAL FRAMEWORK}

We specifically rely on business network theory (Forsgren, Holm, \& Johanson, 2007; Kano \& Verbeke, 2019) to explain why the complexity of a firm's global supply network might influence its IBP. Moreover, we integrate business network theory with the information search literature to provide a more nuanced theoretical framework.

\section{Business Network Theory}

The tenets of business network theory suggest that a firm's ability to embed itself in its extended network of international market relationships (i.e., those outside the home country or in the host countries) is critical for international operations and yields two specific benefits. First, it provides the firm with market knowledge, information, material, and access to the partner firms' specific assets and experiences; and second, it enables the firm to gain external knowhow to develop and implement successful internationalization strategies (Kano \& Verbeke, 2019), as such strategies can be extended to draw on their partners' local networks (while also restricting knowledge spillover to competitors). However, such relationships also pose risks. In particular, a power imbalance may emerge if there is a misalignment between the interests of the partners and those of the focal firm, leading to increased partner management costs and turbulent relational dynamics.

An increase in the complexity in a global supply network may initially provide a firm with the required benefits and access to local markets and operations in host countries; however, issues related to bounded rationality will curtail the benefits of a complex network when complexity increases beyond a certain range. In this case, the MNE could, first, face information processing difficulties due to limited cognitive ability and experiential differences in how key information is understood due to managers' differing backgrounds, abilities, and experience; and second, have difficulty monitoring its partners, potentially leading to opportunistic behavior and a power imbalance in the network which could prevent it reaching the common objective of increased IBP.

Moreover, micro, meso, and macro factors can all trigger risk and uncertainties in a business network, which might limit its benefits to the focal firm. Uncertainties arising due to the differential flow of material and information are defined as micro-level (Sivadasan, Efstathiou, Frizelle, Shirazi, \& Calinescu, 2002). These occur largely due to poorquality partner selection (Geary, Childerhouse, \& Towill, 2002) and managers' inability to direct future strategies (Duncan, 1972; Flynn, Koufteros, $\& \mathrm{Lu}, 2016)$, leading to inconsistencies in the flow of knowledge and material throughout the global supply chain, affecting IBP. Meso-level uncertainty arises when partners retain information for their own benefit rather than passing it on to the focal firm, which therefore faces higher costs to ensure supplier participation in various operations (Flynn et al., 2016; Rabinovich, Knemeyer, \& Mayer, 2007). Finally, the bounded rationality experienced by an MNE (and its managers), as outlined above, raises macro-level uncertainties. Thus, while business networks provide firms with opportunities to do business in international markets, they also raise a range of issues relating to information flow and 
collaboration costs that may prevent a focal firm from recombining knowledge and enhancing IBP. Business network theory also indicates that the embeddedness of an MNE in its global supplier network allows it to create firm-specific advantages (FSAs), which can be exploited across different markets in the future (Katila \& Ahuja, 2002).

Some scholars have differentiated between the risks and benefits of local and distance searches. MNEs may engage in both types (Shijaku, LarrazaKintana, \& Urtasun-Alonso, 2020) within their supplier network, but should be aware that distant searches are riskier and more uncertain than local ones. Both, however, have specific potential benefits: a distant search may create novel solutions, while higher levels of a local search may lead to incremental solutions. Therefore, many studies have advocated that MNEs adopt a balanced approach by undertaking both local and distant searches to ensure they leverage the benefits of both efficiency and novelty (Lavie, Stettner, \& Tushman, 2010). It should also be noted that although an extended supply base offers the firm the chance to undertake both local and distant searches, the increased uncertainty and higher transaction costs that often follow the extension of a supply base may lead to an MNE abandoning distant searches and relying more on local ones (Sharma et al., 2020). Integrating supply base complexity with the business network view may provide a detailed understanding of the relationship between supply base complexity and IBP, as discussed in the next section.

\section{Hypothesis Development}

\section{Horizontal complexity and a firm's IBP}

Modern supply chains manage multiple globally dispersed suppliers to mitigate the supply chain risk in international production and distribution (Choi \& Krause, 2006). Implementing such a strategy for a specific product or service raises the issue of horizontal complexity, defined as the width of the supply base (Lu \& Shang, 2017). Increasing the horizontal complexity of its global supply network improves a firm's IBP in two principal ways. First, it can reduce the firm's dependency on a single supplier in a particular geographical region and allow it to access multiple new suppliers, all of which bring their FSAs and experiential knowledge (Sharma et al., 2020). This knowledge will allow the MNE to assess the relevance of its business, adopt business practices that match the market needs, and increase the value of business operations in host markets. Reduced dependency on a single supplier also reduces micro-level uncertainty, enhancing global production and distribution. Moreover, if there are multiple suppliers of the same component, a focal firm may encourage collaboration among them, potentially generating unique knowledge and thus also reducing mesolevel uncertainty (Corradini \& De Propris, 2017).

Second, the MNE can save on safety stock and inventory costs by splitting orders among multiple suppliers (Lu \& Shang, 2017). Cost reductions of this type have the knock-on benefit of allowing firms to achieve shorter cycle times for new product development and adapt more rapidly to technological changes across multiple international markets (Kotabe, Parente, \& Murray, 2007). Moreover, increases in horizontal complexity (Costantino \& Pellegrino, 2010) reduce suppliers' opportunistic behavior (Sharma et al., 2019), further enhancing the flow of knowledge from suppliers to the focal firm and improving its IBP (Cao \& Zhang, 2011; Wu, Choi, \& Rungtusanatham, 2010).

However, increases in horizontal complexity beyond a certain range may not be beneficial for a firm, as they cause additional risks and increased uncertainty. First, the higher the number of suppliers, the more difficult it is to monitor them to ensure they are sharing information with the focal firm and to check the quality and reliability of the information they do share (Bode \& Wagner, 2015; Lu \& Shang, 2017; Sharma et al., 2020), which increases meso-level uncertainty. Second, a firm and its managers may become overwhelmed by multiple suppliers with unique and locationbased expertise, which causes challenges for information processing. Consistent with the absorptive capacity literature (Pedersen, Larsen, \& Dasí, 2020), a firm has a limited capacity to hold and process information. As mentioned above, increases in horizontal complexity beyond a certain point raise the issue of bounded rationality, which is a major source of macro-level uncertainty. As uncertainty increases, a firm is more likely to restrict itself to local searches, which will yield solutions that may not be easily transferable beyond the local context (Ethiraj \& Levinthal, 2004). Also, an increase in uncertainty implies that a firm will incur significantly higher supplier management costs (Lu \& Shang, 2017), which mitigates the initial cost advantages. Thus, the initial benefit a firm derives from a horizontally complex supply chain in terms of diversified knowledge, ability to conduct distant 
searches, and foster collaboration among suppliers diminishes when increased horizontal complexity causes increased cost, uncertainty, and risks, negatively affecting IBP. Therefore, we hypothesize that:

Hypothesis 1: The horizontal complexity of a focal firm's global supply network increases IBP at a decreasing rate.

\section{Vertical complexity and a firm's IBP}

Vertical complexity refers to the depth of the supply base - the number of suppliers with which a focal firm engages beyond its direct (tier-1) suppliers. A firm can derive multiple benefits from increasing the vertical complexity of its global supply chain. First, lower-tier suppliers can provide market information and other resources that tier- 1 suppliers do not and give the focal firm a wider picture of technological dynamics and competition across global markets. As successful IB operations hinge on access to unique supplier knowledge, the more such knowledge can be harnessed from lower-tier suppliers in a vertically complex supply base, the greater the chance of success. Moreover, the global and diversified knowledge gained from lower-tier suppliers helps firms mitigate the effects of changes in business practices (Turkina \& Van Assche, 2018).

Second, lower-tier suppliers can support the focal firm to exploit existing FSAs and assist in the smarter and more efficient flow of products and services and more effective global manufacturing and distribution operations (Flynn, Huo, \& Zhao, 2010; Lu \& Shang, 2017; Vaccaro, Parente, \& Veloso, 2010). As lower-tier suppliers engage with multiple industries for various reasons, whether business volume, product compatibility, or technological competence, they acquire and can pass on a wide range of practices and tools which will help the focal firm overcome IB operation challenges (Phelps, 2010). Integrating the resources and transferable knowledge gained from grassrootslevel supply partners allows a firm to continually update routines, avoid information obsolescence (Levinthal \& March, 1993; Phelps, 2010), and, hence, maximize IBP.

The third way that increased vertical complexity can positively affect IBP is by providing cost benefits and, at least initially, reducing meso-level uncertainty because the MNE gains information about distant markets to which it might have had no access without lower-tier suppliers. The cost benefits arise when the specializations of suppliers on different tiers are added into the manufacturing processes; firms can pool uncorrelated demand - a vital component for success in international markets due to increased global competition (Reuber, Tippmann, \& Monaghan, 2021) - and economies of scale will follow (Lu \& Shang, 2017).

However, while increases in vertical complexity ensure multiple benefits, they may not bring universal gains. Business network theory suggests it may also cause a rise in uncertainty at the micro, meso, and macro levels, hindering an MNE's ability to manage costs and acquire the knowledge required to operate profitably in international markets, thus negatively affecting IBP. First, increases in vertical complexity increase costs as the firm must manage multiple relationship tiers. When such costs become untenable, a firm may only be able to maintain relationships with local partners, avoiding global suppliers and thus losing access to the secondary and tertiary information rooted in global markets. Second, an increase in vertical complexity may increase uncertainty across the value chain, hindering a firm's ability to access information in another way. A different type of challenge arises from increased micro-level uncertainty as it becomes increasingly difficult in a multitier supply base to create the rules necessary to ensure supplier quality. As each tier may interact differently with others (and co-suppliers on the same tier), moreover, the information gathered may also become more ambiguous (Sharma et al., 2020), further enhancing micro-level uncertainty. Meso-level uncertainty also increases as the interests of lower-tier suppliers may not align with those of the focal firm; further, they may lack strategic assets and be unwilling to share information (Ernst $\&$ Kim, 2002). Third, increases in vertical complexity increase the monitoring costs, fostering opportunistic behavior among lower-tier suppliers (Kano, 2018; Wilhelm, Blome, Bhakoo, \& Paulraj, 2016). The failure to share information caused by such behavior further increases meso-level uncertainty. Finally, supply chain disruption is more likely in a vertically complex supply base, which injects macro-level uncertainties while constraining global manufacturing and distribution, information processing, and absorption (Bode \& Wagner, 2015). Therefore, we hypothesize the following:

Hypothesis 2: The vertical complexity of a focal firm's global supply network increases IBP at a decreasing rate. 


\section{Spatial complexity and a firm's IBP}

The next type of supply chain complexity considered is spatial, which refers to the scattered geographical distribution of a firm's global supply base. As noted, a geographical spread of suppliers brings unique insights to the firm, which are critical for IBP; however, it also increases the costs of managing and monitoring relationships and therefore limits the resources available to seek out new global supply base information and thus negatively affects IBP. Increased spatial complexity may also give rise to multiple uncertainties. On the micro-level, compliance with and adjustment to multiple regulatory and legislative regimes increases ambiguity and absorbs resources that might otherwise be dedicated to knowledge integration (Lu \& Shang, 2017). Geographical distance may also challenge monitoring and thus foster opportunistic behavior among lower-tier suppliers, harming collaboration in the supply chain and the recombination of new knowledge for IBP, inducing meso-level uncertainties (Kano, 2018; Obloj \& Zemsky, 2015). Finally, as geographical dispersion increases, so does the heterogeneity of supplier location. As a result, a bounded rational MNE may find it difficult to integrate information from geographically dispersed suppliers. Hence, increases in uncertainty at multiple levels due to spatial complexity, as with horizontal and vertical complexity, may leave an MNE seeking knowledge and information from local suppliers only, similarly restricting its ability to create new solutions that can be exploited in international markets. In contrast, a wide geographical dispersion of global supply partners gives access to a range of technological proficiencies, as well as different market, cultural, and ethical norms, all of which facilitate risk mitigation and knowledge integration (Guan \& Yan, 2016).

However, a similar picture emerges to that outlined above for horizontal and vertical complexity, namely that the challenges associated with increased spatial complexity may diminish after a certain point, and net growth may not outweigh the increased uncertainty and challenges associated with the greater volume of knowledge to be acquired and integrated. Therefore, we argue that:

Hypothesis 3: The spatial complexity of a focal firm's global supply network decreases IBP at a decreasing rate.

\section{Moderating effects}

Moderating effects of supply base collaboration. The extant global supply chain literature - as well as business network theory - emphasizes the value of supply chain collaboration as it helps leverage partners' resources and knowledge, enhancing performance (Cao \& Zhang, 2011). Collaboration among tier-1 suppliers is especially important as it facilitates innovation and improves cost efficiencies (Potter \& Wilhelm, 2020); when suppliers' interests align, including within a complex supply chain, the focal firm also benefits from reduced supply base uncertainty and coordination costs as well as knowledge spillover among partners (Lu \& Shang, 2017). For example, scholars have also documented such collaborations among Daimler Chrysler's suppliers, where suppliers of seats and instrument panels have collaborated in the new product development process (Choi, Wu, Ellram, \& Koka, 2002; Potter \& Wilhelm, 2020).

From the structural perspective, collaboration exists when network members start developing ties with each other: the greater the number of ties, the greater the collaboration and knock-on effects of knowledge sharing as partners develop norms (Rowley, Behrens, \& Krackhardt, 2000) and joint standards ( $\mathrm{Lu} \&$ Shang, 2017), which will also percolate to the lower-tier suppliers' norms and knowledge-sharing routines (Uzzi, 1997). They are also more likely to sanction each other's opportunistic behavior, should it arise (Coleman, 1988).

Increases in supply base collaboration reflect greater connection intensity among suppliers (Pathak, Wu, \& Johnston, 2014), indicating effective inter-supplier communication, understanding, and knowledge spillover, as well as reduced competition among suppliers. This situation is more likely to emerge when suppliers start collaborating for mutual gains, such as new product development, when they will be less likely to withhold information. In this situation, it is easier for the focal firm to coordinate all partners and rationalize its IB operations, thus curtailing the negative effects of horizontal complexity. Indeed, the spillover of knowledge from the supply base further helps a firm to reduce uncertainties by increasing the visibility of its coordination mechanism and allowed a greater degree of mutual observation among partners. Hence, micro-level uncertainties are reduced as the focal firm gains access to coordinated knowledge; meso-level uncertainties are reduced due to the knowledge spillovers arising from the collaboration among suppliers; and 
macro-level uncertainties are curtailed due to updated information on any disruption coming directly from the supply base. Finally, such collaboration also provides production efficiencies by facilitating manufacturing planning. Hence, we propose that:

Hypothesis 4a: Supply base collaboration in the global supply chain strengthens the relationship between horizontal complexity and a focal firm's IBP.

Increased supply base collaboration also allows suppliers to share information and knowledge across tiers. When a firm's direct suppliers start collaborating, they develop shared norms (Rowley et al., 2000) and joint standards (Lu \& Shang, 2017) which percolate to lower-tier suppliers; moreover, the knowledge spillover that results from a vertically complex supply chain will benefit the focal firm.

The two critical demerits of having a vertically complex global supply network are first a firm's inability to recognize, assimilate, and apply diverse knowledge (Phelps, 2010), and second the increased coordination costs. Although these demerits result in uncertainty across all three levels, micro-level uncertainties can be reduced by the shared norms and standards developed through collaboration, while the same development reduces meso-level uncertainties by facilitating cross-tier monitoring and information sharing. Finally, macro-level uncertainties are reduced because the increased collaboration helps a firm diagnose and manage disruptions, which tend to bedevil vertically complex supply chains. With uncertainties mitigated at all three levels, management costs fall, and cross-tier information is more easily integrated, enhancing the focal firm's ability to create FSAs that can be exploited in international markets. Hence, we argue that:

Hypothesis 4b: Supply base collaboration in the global supply chain strengthens the relationship between vertical complexity and a firm's IBP.

Increased supply base collaboration can curtail the negative effects of having a spatially complex global supply chain in two ways. In terms of microlevel uncertainties, suppliers are less likely to behave opportunistically when collaboration brings increased visibility and shared norms; moreover, more homogenous behaviors across the supply base (Yang, Zhang, \& Xie, 2017) facilitate the smooth passage of information to the focal firm and the information generated is less ambiguous and more easily integrated with the organizational knowledge stock. Meso-level uncertainties are also reduced as suppliers realize that sharing, rather than withholding, information and developing good relationships with each other brings joint benefits, reducing management costs and associated risks. Finally, macro-level uncertainties decline as the suppliers will share information in the network regarding any disruptions. Hence, we propose that:

Hypothesis 4c: Supply base collaboration in the global supply chain weakens the relationship between spatial complexity and a firm's IBP.

Moderating effects of focal firm disintermediation. Focal firm disintermediation can be defined as the situation where tier-1 suppliers form direct relationships with customers (Pathak et al., 2014). Disintermediation may occur on two levels: On the foundational level, it is an industry-wide institutional phenomenon; on a strategic level, it refers to the actions of one player (e.g., the internalization of the intermediary function by an upstream channel member). In this paper, we consider the strategic aspect of disintermediation. Scholars in marketing have used disintermediation in the context of the manufacturer, dealer, and customer relationship (McFarland, Bloodgood, \& Payan, 2008). However, intermediaries may be conceptualized differently under different contexts. For example, in a platform ecosystem, the platform itself acts as the intermediary between sellers and buyers, meaning both can be considered as its customers (Chakravarty, Kumar, \& Grewal, 2014). Operations management scholars have defined supply chain disintermediation as suppliers forming relationships with buyers' customers (Bicer \& Hagspiel, 2016; Pathak et al., 2014). Rossetti and Choi (2005) argue that "Although original equipment manufacturers (OEMs) had implemented strategic sourcing during the past decade, their long-established supply chain was coming apart - suppliers were selling their wares directly to the buyers' customers. We refer to this phenomenon as supply chain disintermediation" (pg. 46). Because of their downstream nature, typical suppliers are non-existent in the conventional disintermediation literature in marketing. In the context of buyer-supplier relationships, marketing research 
has largely focused on supplier-buyer dyads (Shamsollahi, Chmielewski-Raimondo, Bell, \& Kachouie, 2020) and has not explored disintermediation from the perspective of the supplier-focal firm-customer/buyer network. However, if we consider a network (as in our case), the focal firm also acts as an intermediate link, which is the same as in the manufacturer-distributor-retailer-customer context.

Such disintermediation may occur as tier-1 suppliers start forming relationships with the customers and even replace the focal firm, in extreme cases. Two major challenges are associated with focal firm disintermediation. First, from a business network perspective, as more and more suppliers start to connect with the customers, the flow of novel information is disrupted (Ahuja, 2000) because the focal firm loses its brokerage position in the network. Second, micro-level uncertainty increases in tandem with focal firm disintermediation because the focal firm may lose access to key information if suppliers with a direct relationship with that firm's customers may not share information with it.

Despite these negatives, there are certain positives associated with focal firm disintermediation. First, from the perspective of bounded rationality, an increase in connections between suppliers and customers reduces coordination costs (Lu \& Shang, 2017). Second, as the connections between suppliers and customers increase, an embedded relationship develops that may lead to knowledge sharing (Grewal, Lilien, \& Mallapragada, 2006) and the creation of shared norms, preventing opportunistic behavior and reducing meso-level uncertainty (Polidoro et al., 2011). Third, research has shown that disintermediation - that is, when both focal firm and supplier serve the same customer - can lead to constructive dialogue and open discussion on multiple issues, allowing the firm and its suppliers to better understand each other's abilities (Li, Liu, \& Liu, 2011).

Meanwhile, an increase in horizontal complexity implies multiple suppliers for the same component. As argued previously, although greater horizontal complexity provides more novel information, beyond a certain point, it may also enhance risk and uncertainty at the macro, micro, and meso levels, resulting in the focal firm's inability to manage costs and risks in the supply chain and negatively affecting IBP. We argue that an increase in focal firm disintermediation may mitigate some of these concerns at the meso and macro levels.
First, meso-level uncertainty may decrease as it becomes difficult for suppliers to withdraw information. When a supplier and focal firm serve the same customers, a platform is often created for engagement and knowledge sharing (Li et al., 2011). Moreover, due to the embedded nature of such a relationship, the non-sharing of information becomes difficult as the focal firm can gain information from the customer if a supplier does not share it. The embedded nature of the relationship due to focal firm disintermediation also reduces opportunistic behavior, further reducing meso-level uncertainty. Second, macro-level uncertainty may reduce as focal firm disintermediation reduces coordination costs and, hence, the challenges associated with bounded rationality that arise due to increased horizontal complexity. Thus, we propose:

Hypothesis 5a: Focal firm disintermediation in the global supply chain strengthens the relationship between horizontal complexity and a firm's IBP.

Regarding vertical complexity, the challenges emerge due to the existence of multiple supplier tiers in the global value chain. However, focal firm disintermediation may mitigate some of these challenges for the same reasons as outlined above: the dual pressure (from the focal firm and the customers) to monitor their suppliers as well as embedded relationships provide knowledge and information and curtail opportunistic behavior among lower-tier suppliers. Thus, meso-level uncertainty declines, strengthening the relationship between vertical complexity and IBP. Second, the coordination costs (a source of macro-level uncertainties) may decline as suppliers are now connected to the customers, which reduces the pressure on the focal firm to manage a large inventory (Li \& Choi, 2009; Lu \& Shang, 2017). This reduction in coordination costs reduces bounded rationality concerns, thereby mitigating macro-level uncertainty. With a decrease in uncertainty and an increase in the ability to integrate knowledge from various suppliers across international markets, an MNE can counter the challenges associated with vertical complexity. Hence, we argue that:

Hypothesis 5b: Focal firm disintermediation in the global supply chain strengthens the relationship between vertical complexity and a firm's IBP. 
Finally, in terms of spatial complexity, the negative effects on IBP arise from an increase in uncertainty at all levels, which is primarily due to geographical dispersion. As with horizontal and vertical complexity, focal firm disintermediation may reduce this uncertainty, thereby facilitating IBP. However, a key challenge faced by MNEs in geographically diverse markets is that focal firm disintermediation may mitigate their ability to serve as an integrator of knowledge. Prior research has argued that an MNE must act as a metaintegrator of knowledge to achieve success in international markets (Narula, 2014). However, with focal firm disintermediation, an MNE may lose the opportunity to occupy this position in the network. Simply put, while increases in disintermediation may help a firm reduce costs and risk, they may also threaten its strategic position within a geographically dispersed supply chain. Thus, focal firm disintermediation has two different effects on the relationship between spatial complexity and IBP; a priori, it is difficult to argue which effect will dominate. Therefore, we propose two different hypotheses:

Hypothesis $5 \mathrm{c}_{\mathbf{1}}$ : Focal firm disintermediation in the global supply chain strengthens the relationship between spatial complexity and a firm's IBP.

Hypothesis $\mathbf{5 c}_{2}$ : Focal firm disintermediation in the global supply chain weakens the relationship between spatial complexity and a firm's IBP.
Figure 2 presents the comprehensive framework, including all the main and moderating effects.

\section{METHOD}

\section{Data}

To calculate the complexity dimensions, we require information on firms' supply bases, together with their interconnections. We collected data from the Bloomberg Supply Chain Database (SPLC), which, scholars argue, provides the most granular data on supplier relationships (Jacobs \& Singhal, 2020; Osadchiy, Gaur, \& Seshadri, 2016; Sharma et al., 2019). Bloomberg draws upon multiple sources, such as annual reports, SEC filings, earnings calls, press releases, webpages, etc., to collect key buyersupplier relationship information (Jacobs \& Singhal, 2020; Sharma et al., 2020). Jacobs and Singhal (2020) compared the relationships available in Bloomberg SPLC with the information offered by the business press for Volkswagen and found that over $86 \%$ of the unique buyers and suppliers identified in the business press are also present in the Bloomberg database. The major disadvantage of Bloomberg SPLC is that it does not allow the downloading of data, which must, therefore, be collected manually, which is a laborious process. For example, it took Shao, Shi, Choi, and Chae (2018) 15 weeks to establish the Honda supply network. Considering the multitier nature of supply networks, we have created 244 relevant examples. It took us more than 24 months to collect the data through intensive manual labor

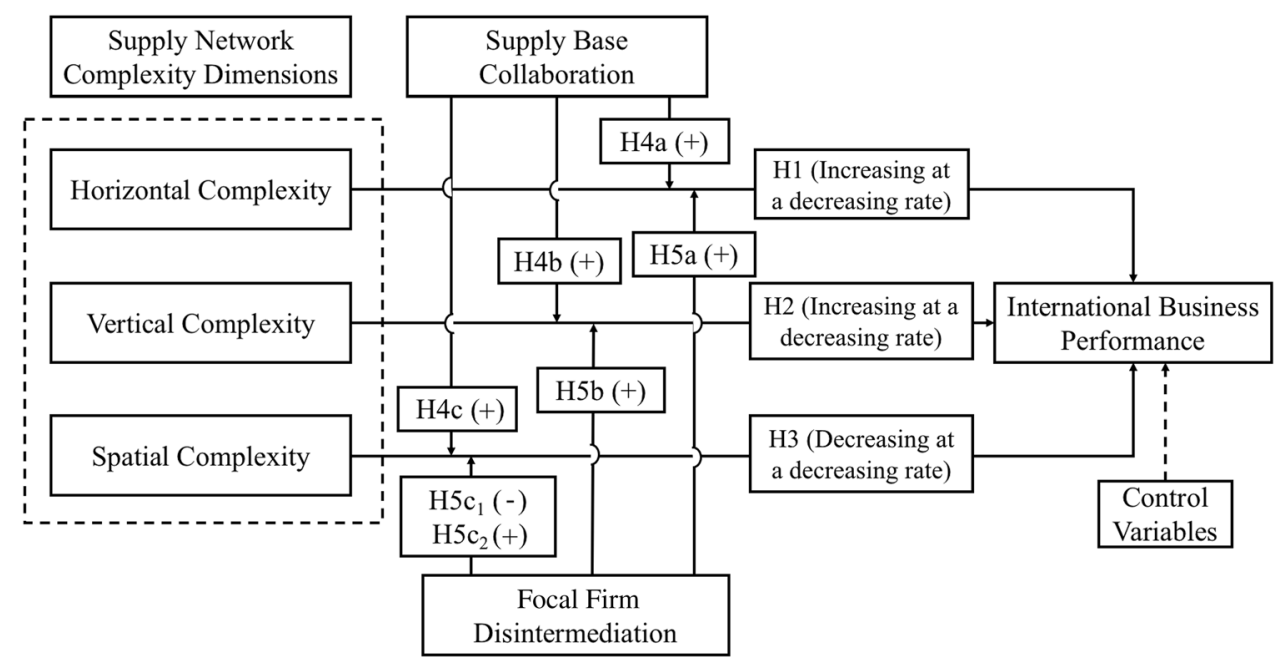

Figure 2 Conceptual framework. 
and the use of up to 12 terminals. The relationships identified in Bloomberg SPLC can be divided into two categories: quantified and unquantified. We consider only quantified relationships, that is, those for which the number of business transactions between the buyer and supplier was available, for the 2012-2017 period.

We followed the sampling method of Sharma et al. (2019) and started with 500 randomly selected firms from the Bloomberg database. Of these, 77 firms are not publicly traded and were therefore dropped from the sample. For 127 firms, there was insufficient tier-2 information. After considering multiple additional sources, we were unable to gather IBP data for 91 other firms or control variable data for 20 firms. Our final dataset, therefore, consisted of 185 firms. We first collected the tier- 1 information of the focal firm and then the tier-2 information for all the tier- 1 suppliers. Figure 1 presents an example of the supply network of Boeing. We created 185 multi-tier global supplier networks for our analyses. Before describing the variables, we provide evidence in the following segment that the supply chains we consider here are global.

\section{Global nature of our sample}

We checked the geographical dispersion of each supply chain in our sample. For example, Boeing had 363 tier-1 suppliers for the year 2016 located in 27 different countries. Our sample for the year 2016 contains 4295 unique firms, spread across 58 different countries, and 14919 unique relationships. WA-Figure 1 represents the geographical spread of all network members and their interconnections in our sample for the year 2016. A similar dispersion was found for the entire sample of data from 2012 to 2017. Again, scholars have argued that an MNE and its subsidiaries may be independent of each other, and thus, a firm's supply chain may not be an adequate representation of all the transactions across the supply chain. We find that most MNEs outside the US do not need to disclose subsidiary information. Hence, we are unable to determine whether our data is complete or not. We revisited the data for some US-based firms and their subsidiaries. We find that suppliers present in subsidiaries' supplier list are also present in the focal firms' supplier list (WASection A for details). For example, BGIL IN, which is a supplier of Siemens India (a subsidiary of Siemens AG), is also present in Siemens AG's supplier list (see WA-Section A Figure 2A for the presence of BGIL IN in Siemens AG's supplier list and WA-Section A Figure 2B for the source document of BGIL IN). Similarly, DVLA IJ, who supplies to Procter \& Gamble Home Products (PGHP) Indonesia (a subsidiary of Procter \& Gamble US), is also present in Procter \& Gamble US supplier list (see WA-Section A Figure 3A for the presence of DVLA IJ in P\&G US's supplier list and WA-Section A Figure 3B for source document of DVLA IJ). We, however, cannot claim that all suppliers who supply to subsidiaries are present in our data. Future research must explore this issue in greater detail. Our results should be interpreted with the caveat that the data may not be complete and with the tacit assumption that subsidiaries transfer information to the MNE and MNE managers take this information into account while formulating strategies.

\section{Distribution of foreign sales to total sales (FSTS)}

In our sample, the foreign sales variable has the following descriptive measures: mean $=21,493.91$ million USD; Std. Dev. = 34,254.87 million USD; minimum $=232.75$ million USD; and maximum $=300,635$ million USD. In terms of foreign sales by total sales (FSTS), mean $=0.59$, Std. Dev. $=0.23$, minimum value $=0.022$, and maximum value $=1$. Hence, in our sample, all the firms have some portion of revenue coming from foreign markets.

\section{Offices outside the home country}

We looked at each firm and its offices outside its home country, relying on multiple databases and anecdotal evidence (including the websites of the firms and their verticals) and found information for 171 of the 185 firms in our sample indicating that, on average, they have 65.97 offices outside the home country (Std. Dev. $=70.83)$.

\section{Variable Operationalization}

\section{Dependent variable: IBP}

Most researchers use return on assets as a measure of performance (Hult et al., 2008). We extended this idea to compute IBP. As we considered performance in international markets rather than performance in general, we computed "international ROA," which is operationalized as the ratio of the values from an MNE's international market revenue to its total assets. This measure has previously been used by Sharma et al. (2019). We first log-transformed the numerator and 
denominator and then took the ratio. This measure is suitable for our context for two reasons. First, from a conceptual perspective, a higher international ROA indicates that an MNE can exploit its existing FSAs in international markets as well as create new ones by combining different resources for exploitation in international markets, hence gaining more revenue in such markets than MNEs with a lower international ROA. Second, we argue that network complexity dimensions have a nonlinear relationship with IBP; hence, MNEs that can better manage complexity dimensions should be able to search for and recombine knowledge from international markets more efficiently than those which cannot manage supplier complexity. Thus, with a similar asset base, MNEs with moderate levels of complexity dimensions must be able to extract more international ROA. Moreover, consistent with the literature, we used the absolute value of profits ${ }^{5}$ from the international market; while this is subjective, it does capture the nuances in international market profits. Third, as a tertiary measure of IBP, we used the ratio of international revenue to total revenue, although this has been heavily criticized due to its ratio nature. Note that the extant IB literature proposes using a firm's value to make this measurement. However, we believe that firm value should drive IBP because this indicates its future potential. Again, prior research has indicated that a higher valuation may negatively influence an MNE's internationalization because an MNE with a positive outlook towards the present and future may not make multiple changes to its IB strategy. In contrast, an MNE with a lower valuation may engage in more risk-seeking avenues, such as selling products and services to international markets (Jung \& Bansal, 2009). Thus, we controlled for firm value (Tobin's q) (Katsikeas, Morgan, Leonidou, \& Hult, 2016). Finally, although the extant literature suggests the use of "growth"-related variables, as complexity emerges only as a slow process, changes in network complexity should not affect the temporal changes in IBP. Although we tested the models using international revenue growth, we did not find significant results.

\section{Independent variables: Horizontal complexity}

Our operationalization of horizontal complexity relied on the extant literature, suggesting that the total number of tier-1 suppliers in a firm's global supplier network represents the network's horizontal complexity (Bode \& Wagner, 2015; Bozarth,

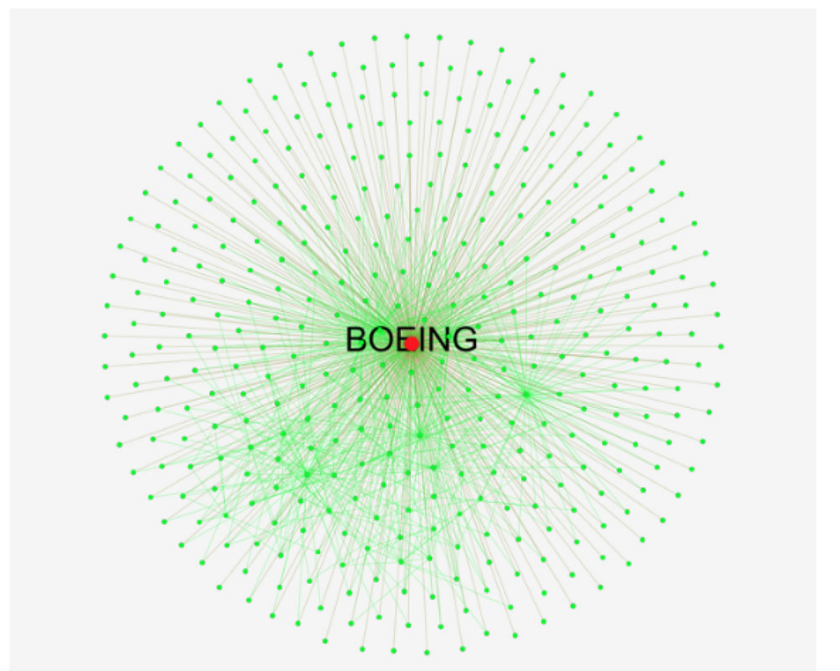

Figure 3 Horizontal complexity of Boeing (Boeing marked as red. Tier 1 suppliers marked as green).

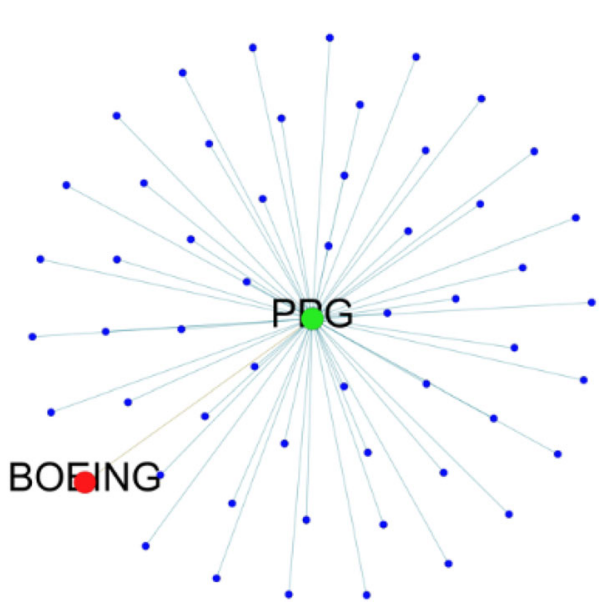

Figure 4 Vertical complexity of Boeing (Boeing is marked as red, one of its tier-1 supplier PPG is highlighted in green. Tier-2 suppliers of Boeing that are Tier-1 suppliers of PPG are highlighted in blue).

Warsing, Flynn, \& Flynn, 2009). Figure 3 represents the horizontal complexity of Boeing. There are 363 tier-1 suppliers, marked in green (see Figure 3 ).

\section{Vertical complexity}

Consistent with the extant literature, we operationalized vertical complexity as the average number of tier-2 buyers and suppliers in a firm's extended global network per tier-1 supplier (Lu \& Shang, 2017). Figure 4 represents the sample vertical complexity of Boeing for one of its tier-1 suppliers, PPG. 


\section{Independent variable: Spatial complexity}

Consistent with the literature (Sharma et al., 2020), spatial complexity refers to the geographic dispersion of the supply base.

$$
\begin{aligned}
S C_{i t} & =\sum_{j=1}^{n} \frac{2 \pi r}{360}\left[\operatorname { a r c c o s } \left[\cos \cos \left(\text { lat }_{j}\right) \cos \cos \left(\text { lon }_{j}\right)\right.\right. \\
& \cos \cos \left(\text { lat }_{i}\right) \cos \cos \left(\operatorname{lon}_{i}\right)+\cos \cos \left(\text { lat }_{j}\right) \sin \sin \left(\text { lon }_{j}\right) \\
& \left.\cos \cos \left(\text { lat }_{i}\right) \sin \sin \left(\operatorname{lon}_{i}\right)+\sin \sin \left(\text { lat }_{j}\right) \sin \sin \left(\text { lat }_{i}\right)\right]
\end{aligned}
$$

where $j$ is the different region in which network members are located for each focal firm $i$ at time $t$. lat and lon represent the latitude and longitude of the region, respectively, measured in degrees. The radius of the Earth $r$ is taken as $6378 \mathrm{~km}$. Our operationalization represents the actual distance of all suppliers from the focal firm; see WA-Section B for the rationalization and demonstration of the computation. We created two measures of spatial complexity. In the first measure, we weighed the distance between the focal firm and each supplier based on the cost allocation to the suppliers. This is the primary measure in our paper. The second operationalization assumed that all suppliers are the same and that a focal firm can gain information irrespective of a supplier's level of economic dependence on it. Analysis with the second operationalization provides directionally consistent results. Figure 5 presents the spatial complexity of Boeing.

\section{Moderation variable: Supply base collaboration}

Supply base collaboration is measured by the level of interconnectedness of tier-1 suppliers ${ }^{6}$ (Lu \& Shang, 2017). Figure 6 presents the supply base collaboration of Boeing.

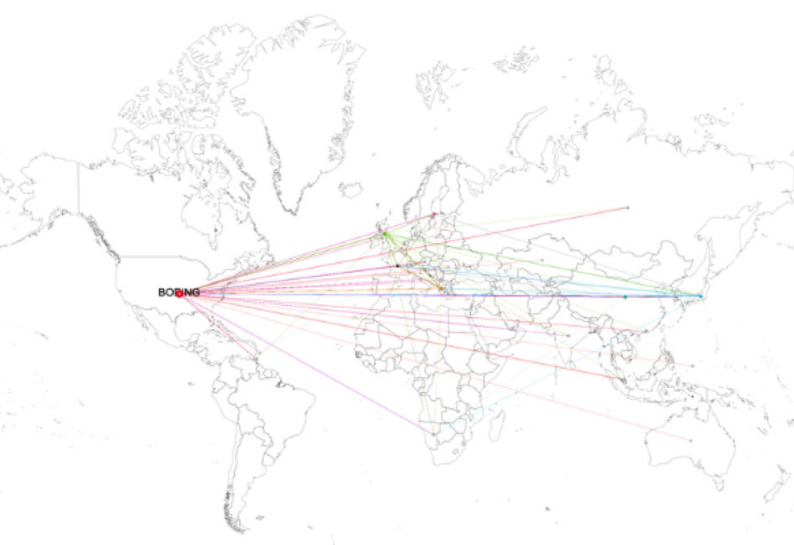

Figure 5 Spatial complexity of Boeing (Boeing marked in red).

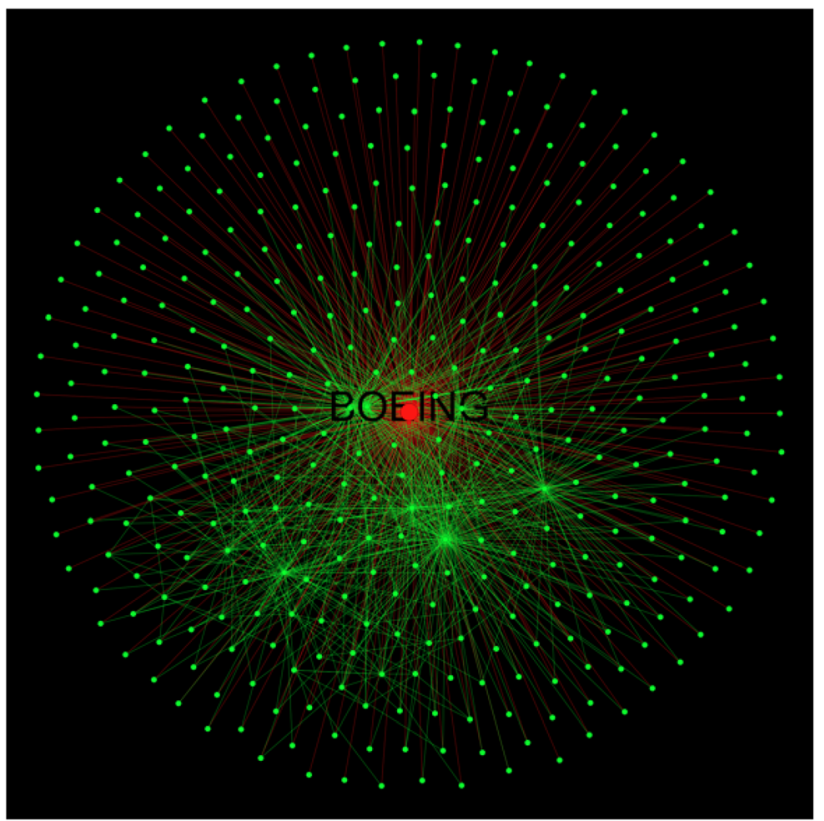

Figure 6 Supply base collaboration of Boeing (green links represents the interconnection among tier-1 suppliers).

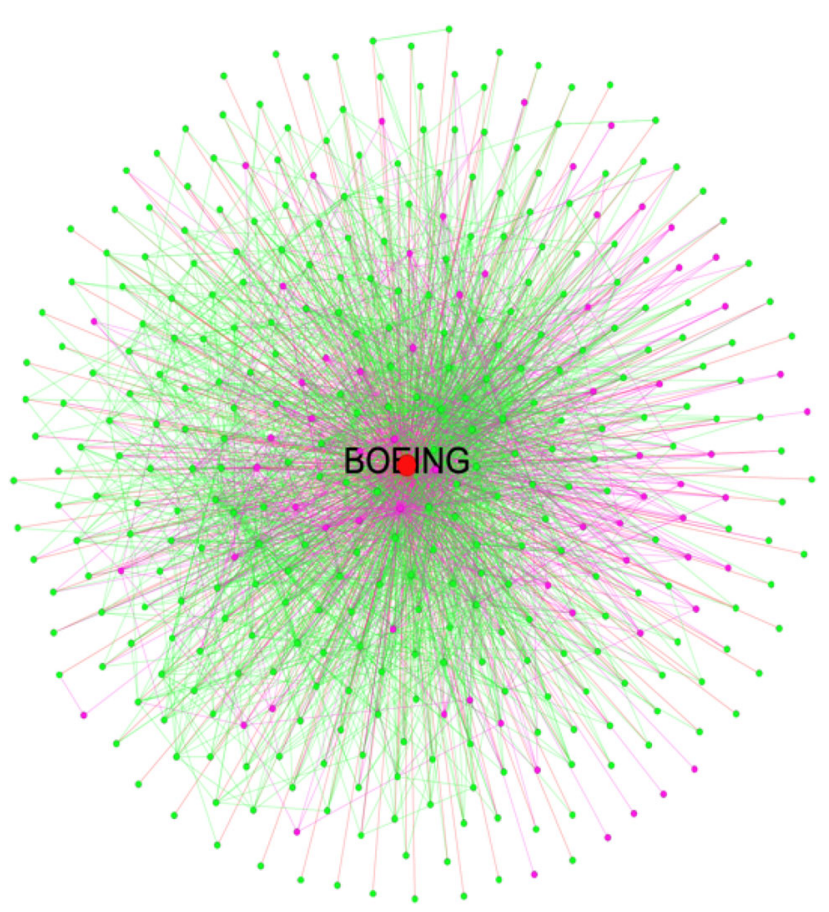

Figure 7 Focal firm disintermediation of Boeing (Tier-1 suppliers of Boeing marked as green. Buyers of Boeing marked as purple. Purple links represent the interconnection of tier 1 of suppliers of Boeing and its customers). 


\section{Moderation variable: Focal firm disintermediation}

Focal firm disintermediation is measured by the level of connection between the focal firm's tier-1 suppliers and buyers (Lu \& Shang, 2017). This demonstrates whether the suppliers can eliminate the focal firm and continue their business directly with its buyers. Figure 7 presents the focal firm disintermediation of Boeing.

\section{Control variables}

We rely on the extant literature that has already shown the importance of the control variables in our study context (i.e., when investigating IBP). We also provide logical arguments for each control variable's importance. We control for multiple variables that may affect a firm's IBP, including a firm's R\&D, and selling, general, and administrative (SG\&A) expenses, as well as the degree to which it prioritizes exploration over exploitation activities (operationalized as the ratio of $\mathrm{R} \& \mathrm{D}$ expenses to SG\&A expenses) (Mizik \& Jacobson, 2003). As a firm's R\&D and SG\&A expenses indicate the intensities of exploration and exploitation activities that have implications for a firm's IB performance, we account for them, consistent with the prior literature (Sharma et al., 2019). Organizational size and financial strength have been found to influence a firm's international businesses and export performance (Ali \& Camp, 1993; Calof, 1994), owing to the fact that organizations with larger size and higher financial strength enjoy greater resources and capabilities that help compete efficiently and effectively to perform well in the global market. Consistent with prior literature, we control for firm size (operationalized as the log of the number of employees) and net income as these may influence IBP (Autio, Sapienza, \& Almeida, 2000). Moreover, as a firm's manufacturing ability, operational efficiency, and asset values determine how the firm will compete in the global market that influence the firm's IB performance, we control for plant and production equipment (PPE) (proxy for a firm's manufacturing ability), inventory turnover (proxy for a firm's operational efficiency), and total assets (Kumar, Borah, Sharma, \& Akella, 2021). Further, a firm's market valuation and shareholders' interest can drive the global business performance as they indicate a firm's quality and reputation; we use Tobin's $\mathrm{q}$ and book value per share to control for firm value and shareholders' interest, respectively (Paul \& Wooster, 2008). Finally, we control for competitive intensity following the annotation of the U.S. Department of
Justice, which states that a market with a Herfindahl-Hirschman Index (HHI) of less than 1500 is considered competitive. Also, a higher $\mathrm{HHI}$ is found to be associated with a firm's IBP (Kirca, Hult, Deligonul, Perryy, \& Cavusgil, 2012). In essence, consideration of a firm's marketing, $R \& D$, size, financial strength, market valuation, inventory, operations, and competition-specific variables, which are justified by the extant literature allow us to cover a range of variables that may influence a firm's IBP to tease out the effects of our hypothesized relationships.

\section{Model Development}

To relate the complexity of a firm's global supplier network with its IBP, we needed an econometric specification that could provide us with the directions (thus helping to assess our hypotheses) and magnitude of the effects. We started with a basic econometric specification, as shown below:

$$
\begin{aligned}
& I B P_{i t}=\alpha+\beta^{H C} \log \left(H C_{i t}\right)+\beta^{V C} \log \left(V C_{i t}\right)+\beta^{S C} \log \left(S C_{i t}\right)+\beta^{S S} S S_{i t} \\
& +\beta^{S S \_H C}\left(\log \left(H C_{i t}\right) \times S S_{i t}\right)+\beta^{S S}{ }^{S C}\left(\log \left(V C_{i t}\right) \times S S_{i t}\right) \\
& +\beta^{S S} \_S C\left(\log \left(S C_{i t}\right) \times S S_{i t}\right)+\beta^{S C L} S C L_{i t} \\
& +\beta^{S C L}{ }_{-} H C\left(\log \left(H C_{i t}\right) \times S C L_{i t}\right)+\beta^{S C L}{ }_{-} V C\left(\log \left(V C_{i t}\right) \times S C L_{i t}\right) \\
& +\beta^{S C L} \_S C\left(\log \left(S C_{i t}\right) \times S C L_{i t}\right)+\sum_{j=1}^{J} \partial_{j} \operatorname{Control}_{i j t}+\varepsilon_{i t}
\end{aligned}
$$

where $\alpha$ represents the intercept.IBP $P_{i t}$ represents the IBP of the ith firm at $t . H C_{i t}, V C_{i t}$, and $S C_{i t}$ represent horizontal, vertical, and spatial complexity, respectively, for the ith firm at time $t . S S_{i t}$ and $S C L_{i t}$ represent the focal firm disintermediation and supply base collaboration of the ith firm at $t$, respectively. The coefficient of the $j$ th control variable is represented by $\partial_{j}$. Note that we used a logarithmic transformation of the focal variables (i. e., HC, VC, and SC) to capture the non-linear effects, as per the hypotheses.

Furthermore, Eq. 2 above did not allow us to capture firm-level unobserved differences. In an augmented functional form, as shown in Eq. 3, we allowed the model to capture the unobserved firmlevel heterogeneity through a random effect specification, whereby the intercept of the model is drawn from a distribution.

As noted in the previous paragraph, the variables of interest in the model (horizontal, vertical, and spatial complexity) do not evolve alone but as a result of managerial competencies decided by each firm's intent and business subjectivity. As such, they can be endogenous. Moreover, the moderating 
variables (supply base collaboration and focal firm disintermediation) similarly result from managerial actions and industry dynamics. Unlike most scholars working in this area, we believe that if there is any chance of such endogeneity, it should be accounted for. Hence, we accounted for the potential endogeneity in the independent variables, that is, horizontal, vertical, and spatial complexity, as well as the moderators, that is, focal firm disintermediation and supply base collaboration, using the control function approach (Petrin \& Train, 2010).

\section{Endogeneity correction}

The control function approach relies on estimating a regression model using the potentially endogenous variable as the dependent variable and at least one instrument as the independent variable that satisfies the conditions of relevance (i.e., theoretically valid and relevant) and exogeneity (i.e., related to endogenous variables, but without the error term or the dependent variable of the proposed model [Eq. 2]). Subsequently, the residuals from the endogenous equation were used as independent variables in the proposed model.

We first estimated the endogenous equations for each endogenous variable. Here, in addition to the instruments that are required by statistical rule and the control function approach, we added a set of control variables to capture as much variance in the endogenous variables as possible. Specifically, we added a firm's R\&D and SG\&A expenses, which can show the level of relationships a firm wants to maintain and, thus, the complexity. We also included the firm's PPE, total assets, size (employees), and operating expenses, which may impact network complexity. Finally, to capture the effects of competition that may help to direct the supplier relationships - and, therefore, complexity - we included $\mathrm{HHI}$ in the first-stage models.

Regarding the instrument variables, we argue that a firm's (specifically, a manager's) decision to develop certain supplier relationships, and thus control complexity, can be rationalized using multiple factors, including the firm's prior experience with the suppliers, the industry dynamics (how other firms in the industry are making key decisions), and the firmographic information. However, information such as prior experience with the suppliers is unobservable for researchers and difficult to measure (due to subjectivity). Furthermore, firmographic information was considered in our model as a control. However, as required for identification purposes, we found instruments relying on the theory of mimetic isomorphism and industry recipe, which suggests that, when there are no other means to map what a firm should do, firms mimic other firms in the industry in terms of managerial decisions. Relying on such precepts, we created the average values of similar firms' horizontal complexity $\left(A H C_{i t}\right)$, average values of similar firms' vertical complexity $\left(A V C_{i t}\right)$, average values of similar firms' spatial complexity $\left(A S C_{i t}\right)$, average values of similar firms' focal firm disintermediation $\left(A S S_{i t}\right)$, and average values of similar firms' supply base collaboration $\left(A S C L_{i t}\right)$. Note that we find the average values by considering the firms in the Global Industry Classification Standard (GICS) that the focal firm belongs to. The correlation of the endogenous variables (log transformed) with the instruments ranges between .08 and .31, whereas the correlation between the instruments and the dependent variable (IBP) ranges between - .018 and .025. We then estimated the endogenous equations, as shown in Eqs. 3a-3e.

$$
\begin{gathered}
H C_{i t}=\gamma^{H C}+\delta^{H C} A H C_{i t}+\theta^{H C} Z_{i t}+\eta_{i t}^{H C} \\
V C_{i t}=\gamma^{V C}+\delta^{V C} A V C_{i t}+\theta^{V C} Z_{i t}+\eta_{i t}^{V C} \\
S C_{i t}=\gamma^{S C}+\delta^{S C} A S C_{i t}+\theta^{S C} Z_{i t}+\eta_{i t}^{S C} \\
S S_{i t}=\gamma^{S S}+\delta^{S S} A S S_{i t}+\theta^{S S} Z_{i t}+\eta_{i t}^{S S} \\
S C L_{i t}=\gamma^{S C L}+\delta^{S C L} A S C L_{i t}+\theta^{S C L} Z_{i t}+\eta_{i t}^{S C L}
\end{gathered}
$$

The residuals from Eq. $3 a-3 e$ (i.e., $\widehat{\eta}_{i t}^{H C}$, $\widehat{\eta}_{i t}^{V C}, \widehat{\eta}_{i t}^{S C}, \widehat{\eta}_{i t}^{S S}$, and $\widehat{\eta}_{i t}^{S C L}$ ) are included in Eq. 2 to arrive at the augmented model, with endogeneity and unobserved heterogeneity included (see Eq. 4) ${ }^{7}$.

$$
\begin{aligned}
& I B P_{i t}=\alpha_{i}+\beta^{H C} \log \left(H C_{i t}\right)+\beta^{V C} \log \left(V C_{i t}\right)+\beta^{S C} \log \left(S C_{i t}\right)+\beta^{S S} S S_{i t} \\
& +\beta^{S S \_H C}\left(\log \left(H C_{i t}\right) \times S S_{i t}\right)+\beta^{S S \_V C}\left(\log \left(V C_{i t}\right) \times S S_{i t}\right) \\
& +\beta^{S S} \_S C\left(\log \left(S C_{i t}\right) \times S S_{i t}\right)+\beta^{S C L} S C L_{i t} \\
& +\beta^{S C L-H C}\left(\log \left(H C_{i t}\right) \times S C L_{i t}\right)+\beta^{S C L_{-} V C}\left(\log \left(V C_{i t}\right) \times S C L_{i t}\right) \\
& +\beta^{S C L}{ }_{-S C}\left(\log \left(S C_{i t}\right) \times S C L_{i t}\right)++\pi^{H C} \widehat{\eta}_{i t}^{H C}+\pi^{V C} \widehat{\eta}_{i t}^{V C}+\pi^{S C} \widehat{\eta}_{i t}^{S C} \\
& +\pi^{S S} \widehat{\eta}_{i t}^{S S}+\pi^{S C L} \widehat{\eta}_{i t}^{S C L}+\sum_{j=1}^{J} \partial_{j} \text { Control }_{i j t}+\varepsilon_{i t}
\end{aligned}
$$

\section{RESULTS}

Table 1 presents the bivariate correlation and descriptive statistics. The highest variance inflation factor $(\mathrm{VIF})=5.41$ for total assets (mean VIF $=2.04$ ), demonstrating that multicollinearity is not critical in the model estimation. While VIF $<5$ is desirable, 


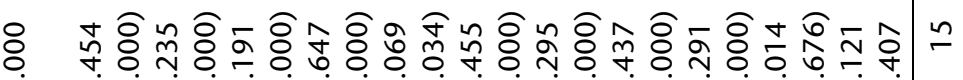

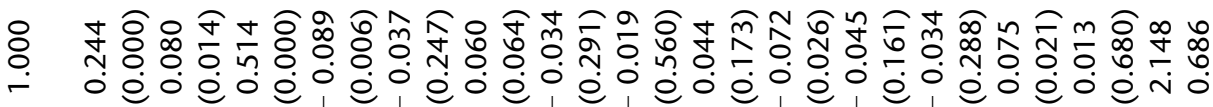

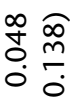

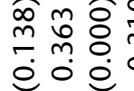

\section{m.}

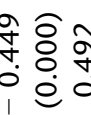

مे ठำ

\section{ธุे}

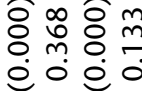

m

0
0
0

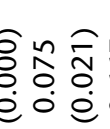

\section{ㅇํㅇำ}

会

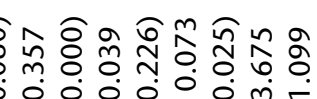

\& - o e o é 


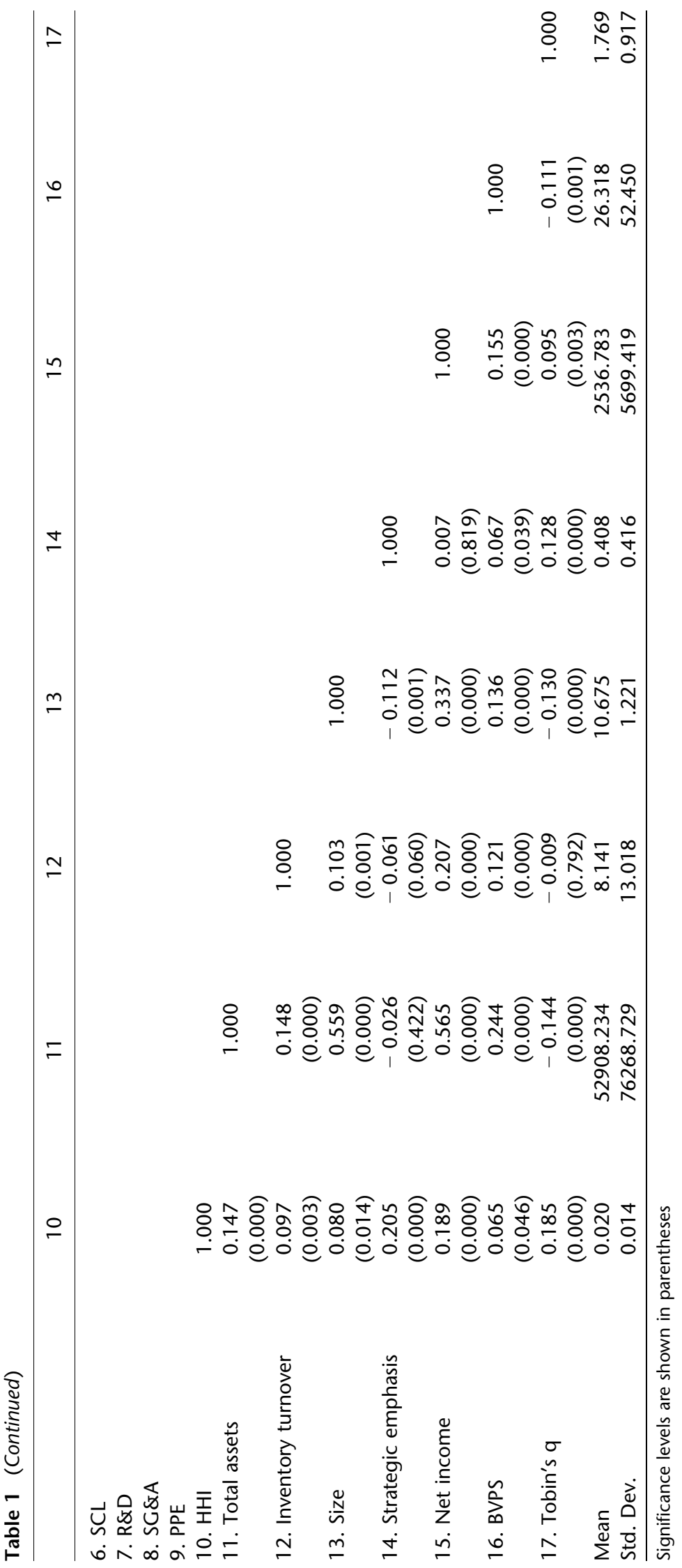


a VIF slightly greater than 5 (but below the cut-off point of 10) is due to the inclusion of multiple firmlevel variables, including net income, in addition to total assets. As explained subsequently, we also estimate two additional models by dropping the control variables; and the results remain directionally consistent, showcasing that multicollinearity is less of a concern here. Moreover, consistent with the extant marketing and IB literature (Kanuri, Chen, \& Sridhar, 2018; Kozlenkova et al., 2021), and given the issues associated with degree of freedom (due to the smaller ratio of sample size to the number of variables) and the exploratory nature of this research (i.e., a new way of looking at global supplier network complexity), we also consider a significance level of 0.1 to analyze the effects of focal variables.

Regarding the results of the first-stage regression models (see Table 2), we found evidence that the average values of similar firms' horizontal complexity $\left(A H C_{i t}\right)(\beta=.0063, p<.01)$, average values of similar firms' vertical complexity $\left(A V C_{i t}\right)(\beta=.0286$, $p<.01)$, average values of similar firms' spatial complexity $\left(A S C_{i t}\right)(\beta=.0001, p<.05)$, average values of similar firms' disintermediation $\left(A S S_{i t}\right)$ $(\beta=.3162, p<.01)$, and average values of similar firms' supply base collaboration $\left(A S C L_{i t}\right)(\beta=.4484$, $p<.01)$ influence a firm's horizontal, vertical, and spatial complexity and focal firm disintermediation and supply base collaboration, respectively. Moreover, a firm's R\&D expenses, total assets, operating expenses, and HHI influence its horizontal complexity, while PPE and size influence its vertical complexity. Also, a firm's SG\&A expenses, total assets, operating expenses, and HHI influence its spatial complexity. We also found evidence that a firm's R\&D and SG\&A expenses, HHI, size, and operating expenses influence focal firm disintermediation. Finally, the results suggest that a firm's total assets, $R \& D$, and size influence its supply base collaboration. The results of the endogenous equations, as reflected in Table 2, outline the importance of endogeneity correction and the inclusion of the control variables in the models in addition to the required instruments.

Table 3 (Model 1) presents the results of the proposed model, which accounts for endogeneity and unobserved heterogeneity. In support of H1, we found that as horizontal complexity increases, a firm's IBP shows a decreasing rate of increase $(\beta=.0107, p<.1)$. Similarly, the effect of vertical complexity on IBP increases at a decreasing rate $(\beta=.0208, p<.05)$, thus supporting $\mathrm{H} 2$.
Meanwhile, we found that the effects of spatial complexity on IBP decrease at a decreasing rate $(\beta=-.0181, p<.1)$, thus supporting H3. The overarching results for the effects of complexity dimensions on IBP reflect the importance of capturing complexity for a firm's IB decisions, especially the formation of global supply relationships and their respective effects on IB decisionmaking.

Moving on to the effects of the moderating variables of supply base collaboration and supply base disintermediation, we found support $(\mathrm{H} 4 \mathrm{c})$ for the conclusion that the effects of spatial complexity on a firm's IBP are weakened $(\beta=.0040, p<.1)$ by an increase in supply base collaboration, indicating that the negative effects of a dispersed global supply chain can be curtailed by increased collaboration (i.e., developing relationships with friendly partners). The results indicate that the effects of horizontal complexity on IBP are strengthened by an increase in supply base disintermediation $(\beta=.0320, p<.05)$, thus supporting H5a. In support of H5b, we found that the effects of vertical complexity on IBP are strengthened by an increase in supply base disintermediation $(\beta=.0312, p<.1)$. Likewise, we found support for $H 5 c_{1}$, that supply base disintermediation strengthens the negative effects of spatial complexity on IBP $(\beta=-.0209, p<.01)$.

Table 3 (Model 1) reflects several additional interesting insights. For example, we see that the coefficients of the residual terms for horizontal complexity $(\beta=-.0138, p<.05)$, vertical complexity $(\beta=-.0210, p<.05)$, spatial complexity $(\beta=.0200, p<.05)$, and supply base collaboration $(\beta=.1227, p<.1)$ are significant, meaning that accounting for endogeneity is very critical, even in the moderating variables, to achieve unbiased and robust results. Moreover, the significance of the standard deviation of the random effect parameter outlines the importance of accounting for unobserved firm-level heterogeneity.

In terms of the control variables, we see that $\mathrm{HHI}$, SG\&A, inventory turnover, net income, and firm value positively impact a firm's IBP. We found that total assets have a marginal negative effect. Note that by controlling net income in the model, we showed the inherent effect that complexity within a firm's global supply chain has on its subsequent IBP.

In addition, we estimated several other benchmark models to show the superiority of the proposed model. Prominent among these are the 


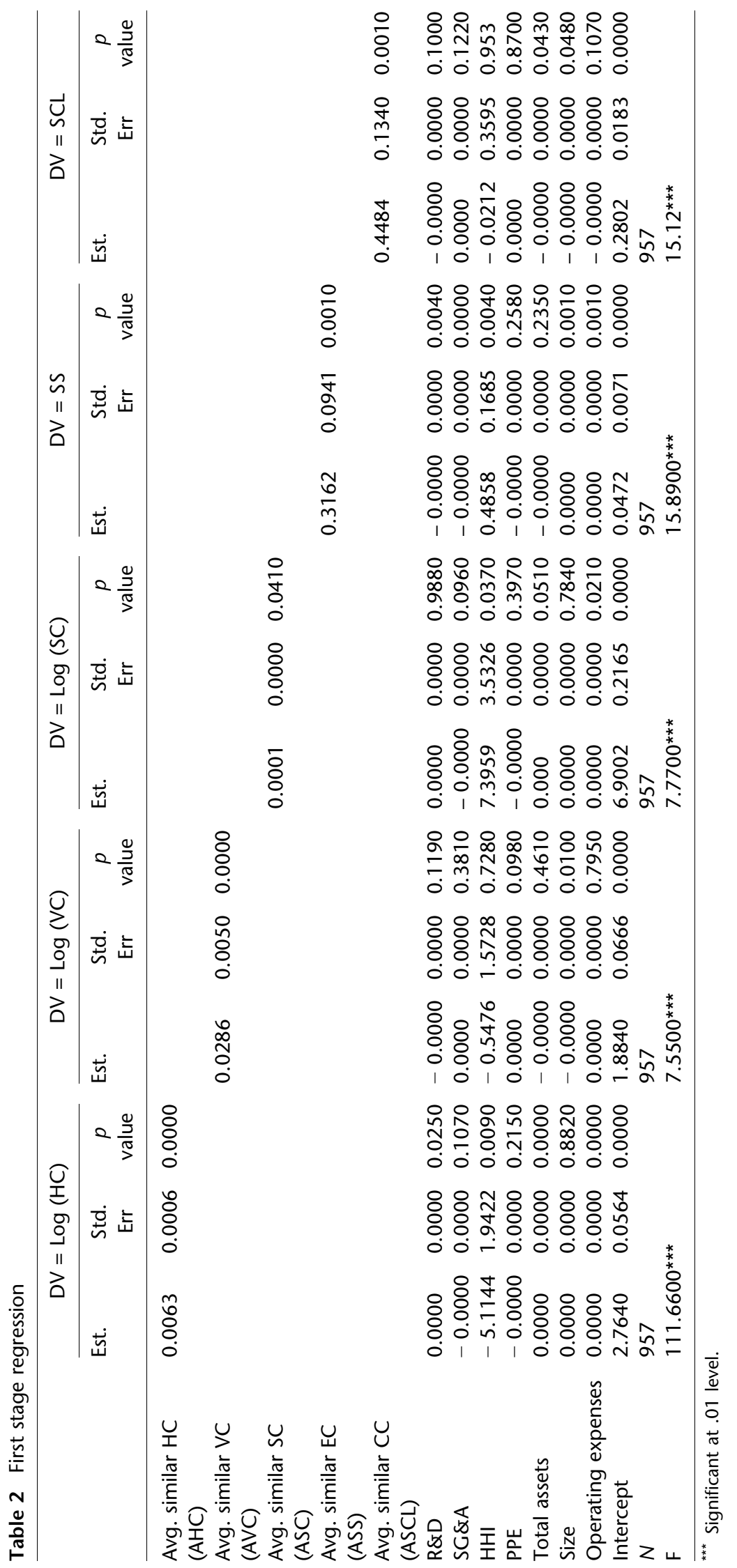




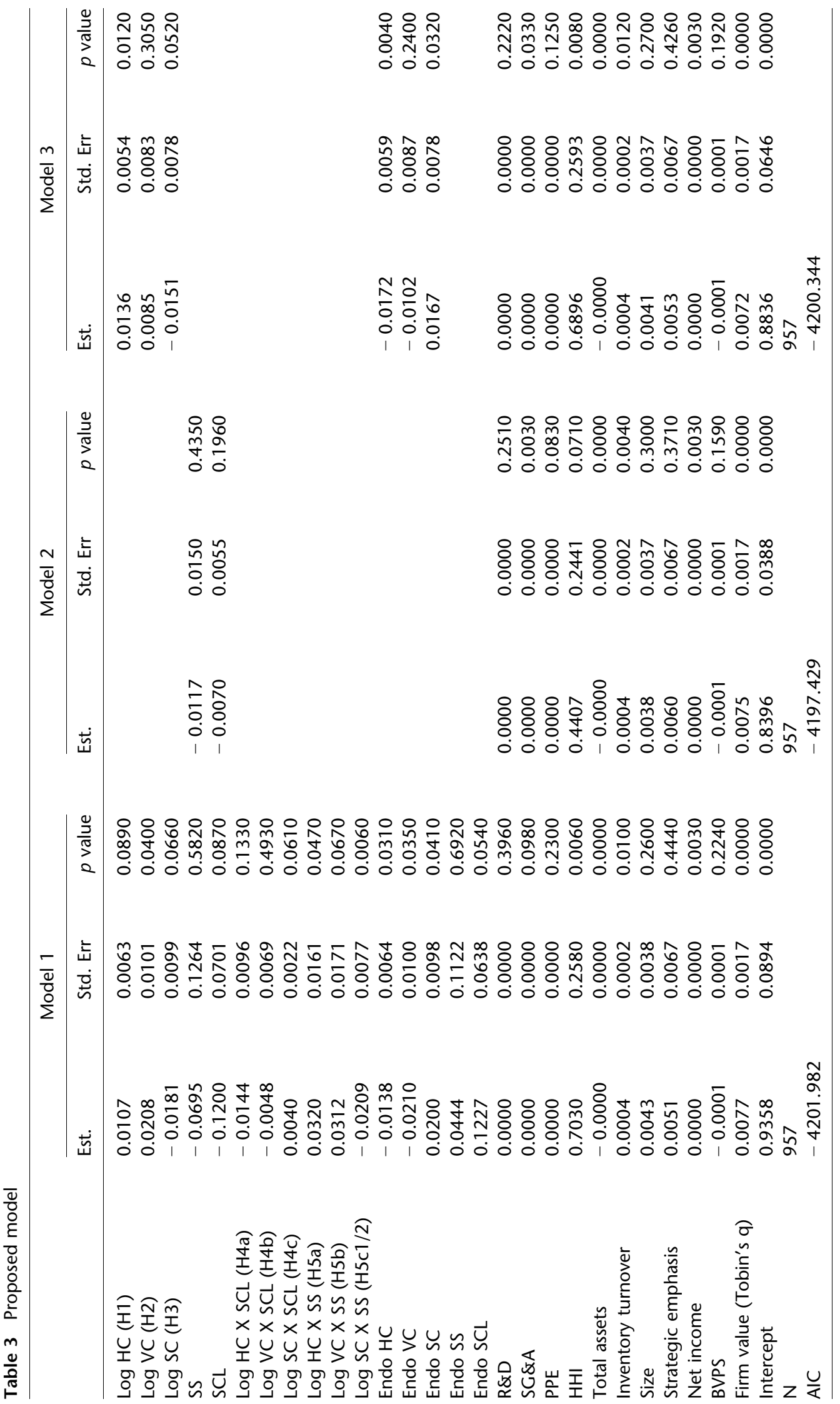


model with only control variables (AIC = 4197.429, Table 3, Model 2) and the model with the main and control variables $(\mathrm{AIC}=-4200.344$, Table 3, Model 3), both of which are inferior to the proposed model performance (AIC $=-4201.982$ ).

Note that depending on the control variables included in a model, the significance level of the primary variables may change. Econometrically, when models face omitted variable issues (i.e., required variables are not included), it may over (under) estimate the strength of an effect, change the sign of an effect, or mask an effect that actually exists, making significant changes in error variance of the variables (Lee, 1982; Green, 1993; Wooldridge, 2009; Clarke, 2005). The changes in the error variance push the standard errors to be larger that may potentially make estimates to be less significant or non-significant. In our context, if we drop variables as in Model 3, the model experiences omitted variable bias that results in altering the significance of one or more variables of interest. Theoretically, to identify the true effects of the variables of interest (HC, VC, and SC), we must consider all possible variables (theoretically driven and control variables to the best-known extent) that may affect IBP. Thus, Model 1 should capture the true effects of the variables of interest in comparison to Model 3, and therefore it is more interpretable in our exploratory nature of this research study.

To ensure that the correlations among the variables are not problematic, we present two additional analyses: a model without control variables (Model 1 in WA-Table 4), and another model after dropping all the controls having correlation greater than .40 (Model 2 in WA-Table 4). As evident in WA-Table 4, results are directionally consistent, and we get support for most of our hypotheses (in comparison to Model 1 in Table 3). However, given that both the models experience omitted variable bias, we do lose significance of one of the focal variables at the .05 level.

\section{ROBUSTNESS ANALYSIS}

\section{Alternate Dependent Variables, Time and Industry Fixed Effects, and Interaction Across Complexity Dimensions}

Our analysis included multiple alternate dependent variables that offer confidence in our results. Mainly, we conducted our first robustness analysis using 'global diversification' (ratio of foreign revenue to total revenue) as the dependent variable. As is evident from WA-Table 5 (Model 1), we found support for most of our hypotheses, with significant effects for horizontal complexity, vertical complexity, and spatial complexity. We were able to collect data on firms' international profits; as discussed earlier, this is a subjective variable that we operationalized using multiple third-party sources. As shown in Model 2 in WA-Table 5, we found support for some of our hypotheses.

We also accounted for time and industry-fixed effects, after which we still see the effects of complexity in the global supply chain on IBP (see WA-Section $\mathrm{C}$ and WA-Table 6 for details). We also tested the model without firm value as a control variable (see WA-Table 7), and the results remained directionally consistent. Finally, we allowed interaction across the complexity dimensions. While the interaction effects are not significant, we also lost the significance of some of the main and moderating effects (see WA-Table 8); hence, we did not consider the interactions in our proposed model.

Controlling for Internationally oriented Variables In an additional analysis, we controlled for the number of foreign subsidiaries, offices outside the home market, and the number of countries in which firms have their foreign operations for 52 firms over time. In this analysis, we tested the effects of complexity dimensions on IBP only, after accounting for internationally oriented variables, as we had a limited number of observations. We did not include these variables in our primary analysis as we have data for a subsample, and two of the three variables are not directly reported by the firms outside the United States (nor they are available in any database or on reporting websites). As shown in WA-Table 9, after controlling for these variables, we found support for $\mathrm{H} 1$ and $\mathrm{H} 3$ (WA-Table 9 Model 1 represents the full model including internationally oriented variables as controls, and WA-Table 9 Model 2 considers only internationally oriented variables as controls).

\section{POST HOC ANALYSIS}

\section{A Firm's Marketing Intensity}

A firm invests significant resources in managing its relationships with suppliers (Jean, Sinkovics, \& Kim, 2010). Although not reported as a specific investment, a firm's investment in suppliers should 
affect the relationship between the complexity dimensions and IBP. In the absence of a primary measure of investment in supplier management, we used a firm's SG\&A expenses to test the relationship. As a firm increases its SG\&A expenses, it will be in a better position to manage suppliers (by building effective communication, delivering trust, and maintaining commitment as per business network theory). Such an increase should positively affect the relationships between complexity and IBP. We estimated the proposed model by including marketing intensity (operationalized as the ratio of SG\&A to total assets) as an additional moderating variable. As reflected in WA-Table 10, we found that increases in marketing intensity reduce the negative effects of spatial complexity on IBP (positive moderation) and strengthen the effects of horizontal complexity on IBP.

Interconnectedness in the Global Supply Network The collaboration variable captures the interconnectedness among the tier- 1 suppliers of the focal firm, excluding the focal firm. However, the interconnectedness among the focal firm and its tier- 1 suppliers is critical as it can alter the negative effects of network complexity (Provan, Fish, \& Sydow, 2007; Rowley et al., 2000). We propose that interconnectedness in the global supply network should influence the effects of supply base complexity on IBP (see WA-Section D for details). We operationalized interconnectedness among supply partners in a firm's global supply chain via "network density", defined as the "ratio of the actual number of ties among network members to the potential number of ties" (Ahuja, 2000; Rowley et al., 2000). We tested the moderating impact of interconnectedness on the proposed relationships. Our results mimic our theoretical assertions. As evident from WA-Table 11, the effects of spatial complexity on IBP are strengthened (negative moderations) by increases in interconnectedness.

\section{IB Experience of TMT Members}

While a firm gains international operation information from multiple sources, the experience of the top management team (TMT) members may play a significant role in assisting it to gain wider knowledge. Building on the arguments in the IB literature concerning the role of top executives in delineating an internationalization pathway (Athanassiou \& Nigh, 2000), we also propose that the international experience of a firm's TMT members can be a source of tremendous benefit in terms of information sourcing and learning. As such, the negative impact of complexity on a firm's global supply chain may be reduced by increases in its $\mathrm{TMT}^{\prime}$ 's international experience. We collect relevant information regarding the international experience of each TMT member for each firm over time from numerous sources, including LinkedIn profiles, Bloomberg descriptions, and media reports, and then average it. The re-estimation of the proposed model with TMT international experience as a contingency effect suggests that the relationship between vertical complexity and IBP is weakened by increases in TMT international experience. Meanwhile, increased TMT international experience reduces the negative effects of spatial complexity on a firm's IBP (see WA-Table 12 for details).

\section{Controlling for Network Structure}

We also estimated a model controlling for the effects of network structure. Specifically, we controlled for the effect of three prominent characteristics of a firm's multi-tier network: density, betweenness centralization, and average clustering coefficient. WA-Table 13 shows that, even after controlling for network structure, we obtained directionally consistent results.

\section{DISCUSSION}

In this study, we investigated the relationships between complexity in a firm's global supply chain and its IBP. Moreover, we tested the contingency effect of supply base collaboration and disintermediation. We summarize our contributions to the literature and practice below.

\section{Contributions to the IB Literature}

First, in terms of adding new knowledge, we argue that, despite in-depth research into the global supply chain within IB, there is little evidence exposing its 'complexity' aspects and how they can affect a firm's IBP. Consequently, we have focused on this unexplored gap. To this stream of the IB literature, the paper brings an additional factor (complexity) that may affect a firm's IBP by introducing a new antecedent (supply network complexity) and determining its effect. Again, we contribute to the literature on marketing by focusing on the buyer-supplier network. Although the network view has gained prominence in the marketing literature in the context of alliances (Fang et al., 2016), limited research has focused on the buyer-supplier network. 
Second, we contribute to the literature on business network theory. While business network theory has acknowledged the role of networks as a source of knowledge and information, it has had limited application to network complexity. Furthermore, most studies in this domain, including those outlining micro-foundations, fail to acknowledge the different dimensions of network complexity. As a result, while business network theory has theoretically indicated that the complex nature of the relationship may play a role in explaining multiple outcomes in international markets, we deepen this understanding by highlighting the non-linear nature of such relationships. Moving against the conventional wisdom that envisages a linear relationship between complexity and performance (Closs, Speier, \& Meacham, 2011), we show that the simple exposition of linear relationships between complexity dimensions and IBP may not actually provide adequate information to develop IB strategies. From the perspective of business network theory, we indicate that the fundamental assumption about the complex nature of a network requires a nuanced understanding of the type of complexity dimensions involved.

Third, we have tested and empirically validated the assumption that collaboration is the network orchestration mechanism through which a firm leverages the benefits of complex relationships, deepening our knowledge of business network theory. Our fourth contribution is the novel introduction of supply base collaboration and focal firm disintermediation as unique moderators, demonstrating that a firm's access to knowledge and resources through a network is contingent on both network complexity and disintermediation. Finally, we have demonstrated an interaction between the visible and invisible dimensions of network complexity within IBP, expanding our foundational knowledge of supply network complexity and answering those scholars who have called for more research on this interaction ( $\mathrm{Lu} \&$ Shang, 2017).

\section{Contributions to IB Practice}

What can IB managers learn from our study? Our findings are in line with the learnings from natural disasters that have taught firms to build and maintain redundancies in their global supply chains to ensure lean, streamlined operations, continuous product availability, and, consequently, smoother system-wide long-term success and profitability. MNEs should continuously monitor complexity in their global supply chains, enact measures when complexity is beyond their control, and/or initiate alternative plans so that the supply chain remains unaffected. We further make multiple contributions to IB practice. First, while evidence suggests that a multitier supply network may affect IBP, we urge managers to take a more holistic view of network complexity. As such, managers must pay close attention to all three dimensions. Horizontal complexity can be managed by understanding the optimal level and considering the quality of tier-1 suppliers. Companies such as Ford have rationalized their supply chain to create an efficient flow of information. Similarly, spatial complexity can be managed by reducing the number of suppliers from distant geographic locations. Although managers should be able to manage the complexity dimensions, not all dimensions have similar effects on IBP. Our paper suggests that pursuing IB opportunities through the global supply base requires a careful evaluation of the multiple complexity dimensions for a manager working in IB operations. Rather than considering all complexities to be negative, a manager must understand that there are optimal points up to which horizontal and vertical complexity can positively affect IBP. In contrast, the negative effects of spatial complexity can only be minimized after a certain level of geographical dispersion is achieved. We offer managers guidance on the different complexity dimensions.

Second, even if a firm is unable to manage its complexity dimensions, our paper provides multiple strategies that can mitigate the challenges associated with network complexity. Our first strategy is to generate supply base collaboration, which efficiently reduces uncertainty in the global supply base and may mitigate the challenges arising due to supply base complexity. The second strategy concerns managing focal firm disintermediation, through which a firm can design future strategies to enhance IBP. This also provides implementable intelligence that can help practitioners increase IBP by managing global supply chain complexity as well as any related collaboration and competition.

Finally, even if a firm finds it difficult to curtail complexity or apply the strategies suggested above, TMT global experience may also mitigate some of the concerns related to global supply chain complexity. However, managers must note that TMT international experience can have differential effects on how complexity impacts IBP. Firms need 
to be cognizant that TMT international experience may only reduce the negative effect of spatial complexity on IBP. Similarly, investing in marketing may also facilitate the management of complexity. Thus, in this paper, we highlight that a firm might either reduce complexity or manage the same through collaboration, TMT international experience, and marketing investment.

\section{LIMITATIONS AND FUTURE RESEARCH DIRECTIONS}

While this is the first study to examine the effect of supply chain complexity on IBP, it has a few limitations. First, our dependent variable only measures the financial performance of a firm. IB research has shown that international market performance must consider various performance matrices, including operational performance (such as market share and productivity) and overall effectiveness performance (such as reputation) (Hult et al., 2008). Again, our performance measure does not consider referents such as industry competition and firm goals (Katsikeas et al., 2016), which may prove vital to assess the marginal effect of complexity on performance. Future research should focus on this aspect in detail. Second, while we consider a novel dataset to compute complexity dimensions, there are a few challenges within our data. Our data come from secondary sources. The extraction of data from a range of secondary sources with differing goals, purposes, and reliability, coupled with different means of data collection and verification (if any), may be a threat to the veracity of these data. However, this also represents a significant advantage for the exploration of new knowledge. While it is difficult to assess the actual mechanisms responsible for the relationship between complexity and IBP, future research may consider the case study approach as well as the use of primary data to explore the relationships we identify here in greater detail. Similarly, our research does not consider the fact that two suppliers may produce the same product. Arguably, such suppliers provide information of an identical nature, yet we do not capture this in our paper. Further, we do not capture the breadth and depth of an MNE's product line, which may also affect the proposed relationships. Future research may look into this aspect. Third, the dynamic nature of the business environment may also affect the relationship between network complexity and IBP. For all firms, the resultant depictions of network complexity may not truly represent the real-world situation. The global organizational structure may influence the supplier network structures and, potentially, performance. However, it is impossible to capture the global organizational structure using secondary data. As firms' global organizational structure may affect their IBP, future research should attempt to collect primary/secondary data to capture such structural issues that may influence complexity in global supply chains. One potential question could be whether environmental munificence, dynamism, and complexity moderate the relationship between supply network complexity and IBP. Finally, one important aspect that the literature has overlooked is the interplay between tier- 1 and tier- 2 suppliers. In most cases, tier-2 suppliers may not have contractual relationships with the focal firm. It is important to understand the role of tier- 1 suppliers in acquiring tier- 2 supplier information and how this may facilitate performance in international markets.

\section{ACKNOWLEDGEMENTS}

Some parts of the data used in this paper have been used in other academic research. We thank the Editor and the anonymous reviewers for their helpful comments. We thank several colleagues at our school and participants at various research seminars for their valuable feedback on earlier versions of the manuscript. We thank Renu for copyediting the manuscript.

\section{NOTES}

${ }^{1}$ In this paper, we use the term "multinational enterprise (MNE)" interchangeably with firms. All firms in our sample earn some percentage of their revenue from international markets, and all have at least four international distribution centers. We also control for the number of foreign subsidiaries, the number of offices outside the host market, and the number of countries where firms have their foreign operations to justify that our sample consists of MNEs. While there is no universally accepted definition of MNEs, we rely on all these criteria to state that our sample comprises MNEs.

${ }^{2}$ International business performance refers to the performance of a firm in international markets or its performance via international operations. 
${ }^{3}$ https://www.mckinsey.com/industries/ advanced-electronics/our-insights/reimaginingindustrial-supply-chains

${ }^{4}$ https://www.accenture.com/_acnmedia/ Accenture/Conversion-Assets/LandingPage/ Documents/Local/1/Accenture-The-MarketIntelligence-Opportunity-Procurement-BPO.pdf

${ }^{5}$ Firms do not report 'international profit' on their balance sheets. To operationalize international profits, we collect information from various sources, including news articles in the public domain from when firms publish their annual reports, news from Lexis Nexis, analyst reports, etc. We locate the international profit information for UPS from https://www.forbes.com/sites/ samanthasharf/2015/04/28/ups-delivers-strongerthan-expected-14-earnings-growth/\#606b82fe32ca and obtain Schlumberger's profit from IB operations using the media link http://calgaryherald. com/business/energy/schlumberger-ceo-expectsfurther-pain-in-oilpatch. Note that many firms report statements such as "IB operations include

\section{REFERENCES}

Ahuja, G. 2000. Collaboration networks, structural holes, and innovation: A longitudinal study. Administrative Science Quarterly, 45(3): 425-455.

Ali, A. J., \& Camp, R. C. 1993. The relevance of firm size and international business experience to market entry strategies. Journal of Global Marketing, 6(4): 91-112.

Andersson, U., Forsgren, M., \& Holm, U. 2002. The strategic impact of external networks: Subsidiary performance and competence development in the multinational corporation. Strategic Management Journal, 23(11): 979-996.

Arregle, J.-L., Miller, T. L., Hitt, M. A., \& Beamish, P. W. 2016. How does regional institutional complexity affect MNE internationalization? Journal of International Business Studies, 47(6): 697-722.

Athanassiou, N., \& Nigh, D. 2000. Internationalization, tacit knowledge and the top management teams of MNCs. Journal of International Business Studies, 31(3): 471-487.

Autio, E., Sapienza, H. J., \& Almeida, J. G. 2000. Effects of age at entry, knowledge intensity, and imitability on international growth. Academy of Management Journal, 43(5): 909-924.

Bartlett, C. A., \& Ghoshal, S. 2002. Managing across borders: The transnational solution. Harvard Business Press.

Basole, R. C., Ghosh, S., \& Hora, M. S. 2018. Supply network structure and firm performance: Evidence from the electronics industry. IEEE Transactions on Engineering Management, 65(1): $141-154$.

Belderbos, R., Leten, B., \& Suzuki, S. 2013. How global is R\&D? Firm-level determinants of home-country bias in R\&D. Journal of International Business Studies, 44(8): 765-786.

Bellamy, M. A., Ghosh, S., \& Hora, M. 2014. The influence of supply network structure on firm innovation. Journal of Operations Management, 32(6): 357-373.

Berchicci, L. 2013. Towards an open R\&D system: Internal R\&D investment, external knowledge acquisition and innovative performance. Research Policy, 42(1): 117-127.

Bicer, I., \& Hagspiel, V. 2016. Valuing quantity flexibility under supply chain disintermediation risk. International Journal of Production Economics, 180: 1-15. approx. $15.6-19.3 \%$ of our total profit." To compute international profits, we take the lower bracket number.

${ }^{6}$ We take the square root transformation to conform with regression assumptions.

${ }^{7}$ Our primary arguments are based on the advantages of knowledge flow associated with supply base complexity and the negative effects arising due to increases in uncertainty and bounded rationality. As each individual dimension may affect these aspects, it is, theoretically, not clear whether the interaction effects will capture any additional information apart from what is being captured by the main effects. Also, in terms of magnitude, we have no theoretical basis for arguing that the combined effect of complexity dimensions will have a greater effect than the sum of the individual effects. Thus, we refrain from testing interaction effects in the proposed model. However, we do capture the interaction effects in a separate analysis; we find consistent results for the main effects.

Blomstermo, A., Eriksson, K., Lindstrand, A., \& Sharma, D. D 2004. The perceived usefulness of network experiential knowledge in the internationalizing firm. Journal of International Management, 10(3): 355-373.

Bode, C., \& Wagner, S. M. 2015. Structural drivers of upstream supply chain complexity and the frequency of supply chain disruptions. Journal of Operations Management, 36: 215-228.

Bos, B., Faems, D., \& Noseleit, F. 2017. Alliance concentration in multinational companies: Examining alliance portfolios, firm structure, and firm performance. Strategic Management Journal, 38(11): 2298-2309.

Bozarth, C. C., Warsing, D. P., Flynn, B. B., \& Flynn, E. J. 2009. The impact of supply chain complexity on manufacturing plant performance. Journal of Operations Management, 27(1): 78-93.

Buckley, P. J., \& Tian, X. 2017. Internalization theory and the performance of emerging-market multinational enterprises. International Business Review, 26(5): 976-990.

Burt, R. S. 1992. Structural hole. Harvard Business School Press.

Burt, R. S. 1997. The contingent value of social capital. Administrative Science Quarterly, 42(2): 339-365.

Calof, J. L. 1994. The relationship between firm size and export behavior revisited. Journal of International Business Studies, 25 (2): 367-387.

Cao, M. \& Zhang, Q. 2011. Supply chain collaboration: Impact on collaborative advantage and firm performance. Journal of Operations Management, 29(3): 163-180.

Chakravarty, A., Kumar, A., \& Grewal, R. 2014. Customer orientation structure for internet-based business-to-business platform firms. Journal of Marketing, 78(5): 1-23.

Chakravarty, A., Zhou, C., \& Sharma, A. 2020. Effect of alliance network asymmetry on firm performance and risk. Journal of Marketing, 84(6): 74-94.

Chandra, Y., \& Wilkinson, I. F. 2017. Firm internationalization from a network-centric complex-systems perspective. Journal of World Business, 52(5): 691-701. 
Chen, T. J. 2003. Network resources for internationalization: The case of Taiwan's electronics firms. Journal of Management Studies, 40(5): 1107-1130.

Choi, T. Y., Dooley, K. J., \& Rungtusanatham, M. 2001. Supply networks and complex adaptive systems: Control versus emergence. Journal of Operations Management, 19(3): 351366.

Choi, T. Y., \& Krause, D. R. 2006. The supply base and its complexity: Implications for transaction costs, risks, responsiveness, and innovation. Journal of Operations Management, 24(5): 637-652.

Choi, T. Y., Wu, Z., Ellram, L., \& Koka, B. R. 2002. Suppliersupplier relationships and their implications for buyer-supplier relationships. IEEE Transactions on Engineering Management, 49 (2): 119-130.

Clarke, K. A. 2005. The phantom menace: Omitted variable bias in econometric research. Conflict Management and Peace Science, 22(4): 341-352.

Closs, D. J., Speier, C., \& Meacham, N. 2011. Sustainability to support end-to-end value chains: The role of supply chain management. Journal of the Academy of Marketing Science, 39 (1): 101-116.

Coe, N. M., \& Hess, M. 2005. The internationalization of retailing: Implications for supply network restructuring in East Asia and Eastern Europe. Journal of Economic Geography, 5(4): 449-473.

Coleman, J. S. 1988. Social capital in the creation of human capital. American Journal of Sociology, 94: S95-S120.

Corradini, C., \& De Propris, L. 2017. Beyond local search: Bridging platforms and inter-sectoral technological integration. Research Policy, 46(1): 196-206.

Costantino, N., \& Pellegrino, R. 2010. Choosing between single and multiple sourcing based on supplier default risk: $A$ real options approach. Journal of Purchasing and Supply Management, 16(1): 27-40.

Crescenzi, R., \& Gagliardi, L. 2018. The innovative performance of firms in heterogeneous environments: The interplay between external knowledge and internal absorptive capacities. Research Policy, 47(4): 782-795.

Duncan, R. B. 1972. Characteristics of organizational environments and perceived environmental uncertainty. Administrative Science Quarterly: 313-27.

Ernst, D. 2005. The complexity and internationalization of innovation: The root causes. Paper presented at proceedings globalization of $R \& D$ and developing countries. Proceedings of the expert meeting Geneva.

Ernst, D., \& Kim, L. 2002. Global production networks, knowledge diffusion, and local capability formation. Research Policy, 31(8-9): 1417-1429.

Etemad, H. 2018. The essence of entrepreneurial internationalization: Managing the dynamic complexity of interactive relationship and reflective adaptations. Journal of International Entrepreneurship, 16(3): 325-337.

Ethiraj, S. K., \& Levinthal, D. 2004. Modularity and innovation in complex systems. Management Science, 50(2): 159-173.

Fang, E., Lee, J., Palmatier, R., \& Han, S. 2016. If it takes a village to foster innovation, success depends on the neighbors: The effects of global and ego networks on new product launches. Journal of Marketing Research, 53(3): 319-337.

Fleming, L. 2001. Recombinant uncertainty in technological search. Management Science, 47(1): 117-132.

Flynn, B. B., Huo, B., \& Zhao, X. 2010. The impact of supply chain integration on performance: A contingency and configuration approach. Journal of Operations Management, 28(1): $58-71$

Flynn, B. B., Koufteros, X., \& Lu, G. 2016. On theory in supply chain uncertainty and its implications for supply chain integration. Journal of Supply Chain Management, 52(3): 3-27.

Forsgren, M., Holm, U., \& Johanson, J. 2007. Managing the embedded multinational: A business network view. Edward Elgar Publishing.
Geary, S., Childerhouse, P., \& Towill, D. R. 2002. Uncertainty and the seamless supply chain. Supply Chain Management Review, 6(4): 52-61.

Germain, R., Claycomb, C., \& Dröge, C. 2008. Supply chain variability, organizational structure, and performance: The moderating effect of demand unpredictability. Journal of Operations Management, 26(5): 557-570.

Gölgeci, I., \& Kuivalainen, O. 2020. Does social capital matter for supply chain resilience? The role of absorptive capacity and marketing-supply chain management alignment. Industrial Marketing Management, 84: 63-74.

Grewal, R., Lilien, G. L., \& Mallapragada, G. 2006. Location, location, location: How network embeddedness affects project success in open source systems. Management Science, 52(7): 1043-1056.

Greene, W. H. 1993. Econometric Analysis (2nd ed. pp. 245246). Berlin: Macmillan.

Grunwald, I., \& Flamm, K. 1985. The global factory: Foreign assembly in international trade. Brookings Institution Press.

Guan, J. C., \& Yan, Y. 2016. Technological proximity and recombinative innovation in the alternative energy field. Research Policy, 45(7): 1460-1473.

Hult, G. T. M., Ketchen, D. J., Jr., Griffith, D. A., Chabowski, B. R., Hamman, M. K., Dykes, B. J., Pollitte, W. A., \& Cavusgil, S. T. 2008. An assessment of the measurement of performance in international business research. Journal of International Business Studies, 39(6): 1064-1080.

Jacobs, B. W., \& Singhal, V. R. 2020. Shareholder value effects of the Volkswagen emissions scandal on the automotive ecosystem. Production and Operations Management, 29(10): 22302251.

Jean, R.-J.B., Sinkovics, R. R., \& Kim, D. 2010. Drivers and performance outcomes of relationship learning for suppliers in cross-border customer-supplier relationships: The role of communication culture. Journal of International Marketing, 18 (1): 63-85.

Johanson, J., \& Vahlne, J.-E. 2009. The Uppsala internationalization process model revisited: From liability of foreignness to liability of outsidership. Journal of International Business Studies, 40(9): 1411-1431.

Jung, J. C., \& Bansal, P. 2009. How firm performance affects internationalization. Management International Review, 49(6): 709-732.

Kano, L. 2018. Global value chain governance: A relational perspective. Journal of International Business Studies, 49(6): 684-705.

Kano, L., \& Verbeke, A. 2019. Theories of the multinational firm: A microfoundational perspective. Global Strategy Journal, 9(1): 117-147.

Kanuri, V. K., Chen, Y., \& Sridhar, S. 2018. Scheduling content on social media: Theory, evidence, and application. Journal of Marketing, 82(6): 89-108.

Katila, R., \& Ahuja, G. 2002. Something old, something new: A longitudinal study of search behavior and new product introduction. Academy of Management Journal, 45(6): 11831194

Katsikeas, C. S., Morgan, N. A., Leonidou, L. C., \& Hult, G. T. M. 2016. Assessing performance outcomes in marketing. Journal of Marketing, 80(2): 1-20.

Kim, S. W. 2007. Organizational structures and the performance of supply chain management. International Journal of Production Economics, 106(2): 323-345.

Kirca, A. H., Hult, G. T. M., Deligonul, S., Perryy, M. Z., \& Cavusgil, S. T. 2012. A multilevel examination of the drivers of firm multinationality: A meta-analysis. Journal of Management, 38(2): 502-530.

Kotabe, M., Parente, R., \& Murray, J. Y. 2007. Antecedents and outcomes of modular production in the Brazilian automobile industry: A grounded theory approach. Journal of International Business Studies, 38(1): 84-106. 
Kozlenkova, I. V., Lee, J. Y., Xiang, D., \& Palmatier, R. W. 2021. Sharing economy: International marketing strategies. Journal of International Business Studies, 1-29.

Kumar, V., Borah, S. B., Sharma, A., \& Akella, L. Y. 2021. Chief marketing officers' discretion and firms' internationalization: An empirical investigation. Journal of International Business Studies, 52(3): 363-387.

Lavie, D., Stettner, U., \& Tushman, M. L. 2010. Exploration and exploitation within and across organizations. Academy of Management Annals, 4(1): 109-155.

Lee, L. F. 1982. Specification error in multinomial logit models: Analysis of the omitted variable bias. Journal of Econometrics, 20(2): 197-209.

Levinthal, D. A., \& March, J. G. 1993. The myopia of learning. Strategic Management Journal, 14(S2): 95-112.

Li, M., \& Choi, T. Y. 2009. Triads in services outsourcing: Bridge, bridge decay and bridge transfer. Journal of Supply Chain Management, 45(3): 27-39.

Li, Y., Liu, Y., \& Liu, H. 2011. Co-opetition, distributor's entrepreneurial orientation and manufacturer's knowledge acquisition: Evidence from China. Journal of Operations Management, 29(1-2): 128-142.

Lu, G., \& Shang, G. 2017. Impact of supply base structural complexity on financial performance: Roles of visible and notso-visible characteristics. Journal of Operations Management, 53: 23-44.

McFarland, R. G., Bloodgood, J. M., \& Payan, J. M. 2008. Supply chain contagion. Journal of Marketing, 72(2): 63-79.

Mizik, N., \& Jacobson, R. 2003. Trading off between value creation and value appropriation: The financial implications of shifts in strategic emphasis. Journal of Marketing, 67(1): 63-76.

Narula, R. 2014. Exploring the paradox of competence-creating subsidiaries: Balancing bandwidth and dispersion in MNEs. Long Range Planning, 47(1-2): 4-15.

Nell, P. C., \& Andersson, U. 2012. The complexity of the business network context and its effect on subsidiary relational (over-) embeddedness. International Business Review, 21(6): 1087-1098.

Obloj, T., \& Zemsky, P. 2015. Value creation and value capture under moral hazard: Exploring the micro-foundations of buyer-supplier relationships. Strategic Management Journal, 36(8): 1146-1163.

Osadchiy, N., Gaur, V., \& Seshadri, S. 2016. Systematic risk in supply chain networks. Management Science, 62(6): 17551777.

Pathak, S. D., Dilts, D. M., \& Biswas, G. 2007. On the evolutionary dynamics of supply network topologies. IEEE Transactions on Engineering Management, 54(4): 662-672.

Pathak, S. D., Wu, Z., \& Johnston, D. 2014. Toward a structural view of co-opetition in supply networks. Journal of Operations Management, 32(5): 254-267.

Paul, D. L., \& Wooster, R. B. 2008. Strategic investments by US firms in transition economies. Journal of International Business Studies, 39(2): 249-266.

Pedersen, T., Larsen, M. M., \& Dasí, À. 2020. Searching locally and globally: Applying Daniel Levinthal's scholarship to international business. Journal of International Business Studies, 51(9): 1532-1546.

Petrin, A., \& Train, K. 2010. A control function approach to endogeneity in consumer choice models. Journal of Marketing Research, 47(1): 3-13.

Phelps, C. C. 2010. A longitudinal study of the influence of alliance network structure and composition on firm exploratory innovation. Academy of Management Journal, 53(4): 890913.

Polidoro, F., Jr., Ahuja, G., \& Mitchell, W. 2011. When the social structure overshadows competitive incentives: The effects of network embeddedness on joint venture dissolution. Academy of Management Journal, 54(1): 203-223.

Potter, A., \& Wilhelm, M. 2020. Exploring supplier-supplier innovations within the Toyota supply network: A supply network perspective. Journal of Operations Management, 66 (7-8): 797-819.

Provan, K. G., Fish, A., \& Sydow, J. 2007. Interorganizational networks at the network level: A review of the empirical literature on whole networks. Journal of Management, 33(3): 479-516.

Rabinovich, E., Knemeyer, A. M., \& Mayer, C. M. 2007. Why do Internet commerce firms incorporate logistics service providers in their distribution channels?: The role of transaction costs and network strength. Journal of Operations Management, 25(3): 661-681.

Reuber, A. R., Tippmann, E., \& Monaghan, S. 2021. Global scaling as a logic of multinationalization. Springer.

Rossetti, C., \& Choi, T. Y. 2005. On the dark side of strategic sourcing: Experiences from the aerospace industry. Academy of Management Perspectives, 19(1): 46-60.

Rowley, T., Behrens, D., \& Krackhardt, D. 2000. Redundant governance structures: An analysis of structural and relational embeddedness in the steel and semiconductor industries. Strategic Management Journal, 21(3): 369-386.

Rugman, A. M., \& Verbeke, A. 2008. Internalization theory and its impact on the field of international business. In J. J. Boddewyn (Ed.), International Business Scholarship: AlB Fellows on the First 50 Years and Beyond (Research in Global Strategic Management): 155-174, vol. 14. Emerald Group Publishing Limited.

Rugman, A. M., \& Verbeke, A. 1992. A note on the transnational solution and the transaction cost theory of multinational strategic management. Journal of International Business Studies, 23(4): 761-771.

Rullani, E. 1993. Networks and internationalization: Managing complexity through knowledge. Perspectives on strategic change. Springer.

Shamsollahi, A., Chmielewski-Raimondo, D. A., Bell, S. J., \& Kachouie, R. 2020. Buyer-supplier relationship dynamics: A systematic review. Journal of the Academy of Marketing Science, 49(2): 418-436.

Shao, B. B., Shi, Z. M., Choi, T. Y., \& Chae, S. 2018. A dataanalytics approach to identifying hidden critical suppliers in supply networks: Development of nexus supplier index. Decision Support Systems, 114: 37-48.

Sharma, A., Kumar, V., Yan, J., Borah, S. B., \& Adhikary, A. 2019. Understanding the structural characteristics of a firm's whole buyer-supplier network and its impact on international business performance. Journal of International Business Studies, 50(3): 365-392.

Sharma, A., Pathak, S., Borah, S. B., \& Adhikary, A. 2020. Is it too complex? The curious case of supply network complexity and focal firm innovation. Journal of Operations Management, 66(7-8): 839-865.

Shijaku, E., Larraza-Kintana, M., \& Urtasun-Alonso, A. 2020. Network centrality and organizational aspirations: A behavioral interaction in the context of international strategic alliances. Journal of International Business Studies, 51(5): 813828.

Shipilov, A., \& Gawer, A. 2020. Integrating research on interorganizational networks and ecosystems. Academy of Management Annals, 14(1): 92-121.

Simon, H. A. 1972. Theories of bounded rationality. Decision and Organization, 1(1): 161-176.

Sivadasan, S., Efstathiou, J., Frizelle, G., Shirazi, R., \& Calinescu, A. 2002. An information-theoretic methodology for measuring the operational complexity of supplier-customer systems. International Journal of Operations \&amp; Production Management, 22(1): 80-102.

Turkina, E., \& Van Assche, A. 2018. Global connectedness and local innovation in industrial clusters. Journal of International Business Studies, 49(6): 706-728.

Uzzi, B. 1997. Social structure and competition in interfirm networks: The paradox of embeddedness. Administrative Science Quarterly: 35-67. 
Vaccaro, A., Parente, R., \& Veloso, F. M. 2010. Knowledge management tools, inter-organizational relationships, innovation and firm performance. Technological Forecasting and Social Change, 77(7): 1076-1089.

Wilhelm, M. M., Blome, C., Bhakoo, V., \& Paulraj, A. 2016. Sustainability in multi-tier supply chains: Understanding the double agency role of the first-tier supplier. Journal of Operations Management, 41: 42-60.

Wooldridge, I. M. 2009. Omitted Variable Bias: The Simple Case. Introductory Econometrics: A Modern Approach (pp. 89-93). Cengage Learning.

Wu, Z., Choi, T. Y., \& Rungtusanatham, M. J. 2010. Suppliersupplier relationships in buyer-supplier-supplier triads: Implications for supplier performance. Journal of Operations Management, 28(2): 115-123.

Yang, Z., Zhang, H., \& Xie, E. 2017. Relative buyer-supplier relational strength and supplier's information sharing with the buyer. Journal of Business Research, 78: 303-313.

Zhou, K. Z., Brown, J. R., Dev, C. S., \& Agarwal, S. 2007. The effects of customer and competitor orientations on performance in global markets: A contingency analysis. Journal of International Business Studies, 38(2): 303-319.

\section{ABOUT THE AUTHORS}

Amalesh Sharma is Assistant Professor of Marketing at the Mays Business School at Texas A\&M University. His substantive areas of interest include B2B relationships, innovation, marketing-mix decisions, customer analytics, and international business. His research focuses on solving managerial issues through state-of-the art methodologies.
V. Kumar (VK) has been honored as a Legend in Marketing through the Legends in Marketing series published by Sage Publications; He has published over 300 scholarly papers and 30 books and has received over 25 Research and Teaching Excellence Awards and 19 Lifetime Achievement Awards (www.drvkumar.com and www.vkclv.com).

Sourav Bikash Borah is Assistant Professor in Marketing at IIM Ahmedabad. He has completed his doctoral studies in marketing from IIM Bangalore. His research interests are in the domains of international marketing, services marketing, and network theory. He has published papers in multiple premiere journals, including the Journal of International Business Studies and the Journal of Operations Management.

Anirban Adhikary is Associate Professor of operations management, quantitative methods and information systems area at Indian Institute of Management Udaipur, India. His research interest includes operational issues in firms' supply chain management and firm performance. He has published papers in multiple top-tier academic journals.

Publisher's Note Springer Nature remains neutral with regard to jurisdictional claims in published maps and institutional affiliations.

Accepted by Saeed Samiee, Area Editor, 13 October 2021. This article has been with the authors for three revisions. 